\title{
Driver Steering Control and Full Vehicle Dynamics Study Based on a Nonlinear Three-Directional Coupled Heavy-Duty Vehicle Model
}

\author{
S. H. Li and J. Y. Ren \\ School of Mechanical Engineering, Shijiazhuang Tiedao University, Shijiazhuang 050043, China \\ Correspondence should be addressed to S. H. Li; lshsjz@163.com
}

Received 14 August 2014; Accepted 27 November 2014; Published 24 December 2014

Academic Editor: Hongbin Zhang

Copyright (c) 2014 S. H. Li and J. Y. Ren. This is an open access article distributed under the Creative Commons Attribution License, which permits unrestricted use, distribution, and reproduction in any medium, provided the original work is properly cited.

Under complicated driving situations, such as cornering brake, lane change, or barrier avoidance, the vertical, lateral, and longitudinal dynamics of a vehicle are coupled and interacted obviously. This work aims to propose the suitable vehicle and driver models for researching full vehicle dynamics in complicated conditions. A nonlinear three-directional coupled lumped parameters (TCLP) model of a heavy-duty vehicle considering the nonlinearity of suspension damping and tire stiffness is built firstly. Then a modified preview driver model with nonlinear time delay is proposed and connected to the TCLP model to form a driver-vehicle closed-loop system. The presented driver-vehicle closed-loop system is evaluated during a double-lane change and compared with test data, traditional handling stability vehicle model, linear full vehicle model, and other driver models. The results show that the new driver model has better lane keeping performances than the other two driver models. In addition, the effects of driver model parameters on lane keeping performances, handling stability, ride comfort, and roll stability are discussed. The models and results of this paper are useful to enhance understanding the effects of driver behaviour on full vehicle dynamics.

\section{Introduction}

Due to rapid development of highway transportation, the research in the field of vehicle dynamics and control systems has attracted many scholars' attention. In order to simulate different driving scenarios and reduce test cost, a lot of driver steering control models have been proposed. However, although automobile and driver form a couple, the aim and reason of the present investigations are often focused either on the vehicle or on the driver. Plochl and Edelmann [1] and MacAdam [2], respectively, gave a detailed review of driver models and their application in automobile dynamics. Among many different driver models, the single- or multipoint preview driver models play an important role. Guo and Guan $[3,4]$ proposed a single-point preview optimal curvature model that has been widely used. Sharp [5] added a low-pass road excitation filter to a single-point time-invariant optimal preview control and calculated the optimal control variable value based on the state space equations. Legouis et al. [6] proposed two driver models with fixed gains and linear or nonlinear time delay. Liu et al. $[7,8]$ used these two models to study the nonlinear lateral dynamics of a $2 \mathrm{DOF}$ vehicle model. Liu et al. [9] established a fuzzy-PID driver steering model for a truck and adjusted the gains by fuzzy rule. Besides above single-point preview models, some multipoint preview models are also widely used. One of the most well-known multipoint preview models is MacAdam's driver model, which is based on the preview control framework for linear systems and calculates the average position deviation during the preview time [10]. Ungoren and Peng [11] proposed a generalized version of the MacAdam's model that can simulate steering actions of human drivers with different driving styles. Chatzikomis and Spentzas [12] presented a combined longitudinal-lateral controller by modifying Sharp' multipoint preview model [13]. Pick and Cole [14] extended a multipoint preview path-following controller to include the muscle reflex control loop and steering torque feedback. It should be noted that most substantial progress in driver modeling still lies in a linear world and focuses on two-axle cab car. However, the investigation on steering control of the 
three-axle heavy vehicles with nonlinear suspension and tire property is also necessary and has attracted some scholars' attention. The UMTRI's yaw-roll truck model described in [15] considered nonlinearities of suspension and tire cornering force as tabular functions and was further adapted to include the road roughness effect [16] but did not set up the difference equations for the longitudinal motion and was only suitable to constant-speed driving conditions.

In addition, the present driver models are often applied to evaluate lateral and yaw dynamic characteristics based on the handling stability vehicle model, and the results about the effect of driver behavior on vehicle vertical, lateral, and longitudinal dynamics are still inadequate. In fact, the road surface offers not only lateral and longitudinal forces to a vehicle but also vertical forces to suspension, especially under complicated driving situations such as lane change, cornering, or barrier avoidance. In these cases, the vertical, roll, and pitch dynamics of a vehicle are coupled with the lateral and yaw motions obviously. Due to bigger inertia, longer wheelbase, and higher roll center compared with cab cars, the heavy-duty vehicles show poorer stability and greater threedirectional coupling effects when entering a turn or lane change. Hence, it is quite necessary to build a three-directional coupled vehicle model and research the effect of driver steering on full vehicle dynamics.

This work applies a modified preview driver model in full vehicle dynamics simulation of a heavy vehicle and investigates the effect of driver parameters on both lane keeping performances and full vehicle dynamic characteristics. Firstly, we give a description on how to model the three-directional coupling effect and nonlinear properties of suspension and tire in a heavy-duty vehicle. Then a modified single-point preview driver control model with nonlinear time delay considering vehicle speed variation is proposed and a driver-vehicle closed-loop system is constructed. The full vehicle dynamic responses of the closed-loop system in double-lane change are obtained by numerical integration. The validity of this closed-loop system is verified by comparison with the results of a field test, the traditional steering stability vehicle model, the linear vehicle model and other driver control models. Finally, the effects of driver model parameters such as vehicle running speed, time delay, preview distance, and permit position error on the path-following behavior and threedirectional dynamics of the vehicle are also analyzed.

\section{Model Building}

2.1. The Nonlinear Three-Directional Coupled Vehicle Model. A nonlinear TCLP model for a three-axial heavy-duty truck with 23-DOF is presented, as shown in Figure 1. The vehicle is front wheel steered and rear wheel driven. $z_{c}, \theta_{c}, \phi_{c}, z_{b}$, $\theta, \phi$ stand for the vertical, pitch, and roll displacements of driver cab and vehicle body. $\psi, x, y$ represent the yaw, longitudinal, and lateral displacements of the full vehicle. $z_{u i}, \phi_{u i}(i=1-3)$ denote the vertical and roll displacements of three wheel axles. $\theta_{p 1}$ and $\theta_{p 2}$ are the pitch angles of the left or right balancing pole on rear suspension. $M, M_{b}$, and $M_{c}$ denote the masses of full vehicle, vehicle body, and driver cab, respectively. The origin of vehicle coordinate system $(x, y, z)$ is located in the intersection between the roll axle and the vertical line passing vehicle center of gravity. $h_{s}$ and $l_{s}$ are the vertical and longitudinal distance from the sprung mass center of gravity to the coordinate origin. $d_{t 1}$ and $d_{t 2}$ are the front and rear wheel track width. $d_{s 1}$ and $d_{s 2}$ are the lateral distance between left and right springs on front or rear suspension.

The movements of the heavy-duty vehicle are coupled with each other greatly. Equations (1) give the longitudinal, lateral, and yaw dynamics of the full vehicle. Equations (2) give the vertical, roll, and pitch dynamics of the sprung mass

$$
\begin{aligned}
M(\ddot{x} & -\dot{y} \dot{\psi})+M_{b} \dot{z}_{b} \dot{\theta}+M_{b} h_{s} \ddot{\theta}-M_{b} l_{s}\left(\dot{\psi}^{2}+\dot{\theta}^{2}\right) \\
= & \left(F_{t x 11}+F_{t x 12}\right) \cos \delta-\left(F_{t y 11}+F_{t y 12}\right) \sin \delta \\
& +\sum_{i=2}^{3} \sum_{j=1}^{2} F_{t x i j}, \\
M(\ddot{y}+ & \dot{x} \dot{\psi})-M_{b} \dot{z}_{b} \dot{\varphi}-M_{b} h_{s} \ddot{\varphi} \\
= & \left(F_{t x 11}+F_{t x 12}\right) \sin \delta+\left(F_{t y 11}+F_{t y 12}\right) \cos \delta \\
& +\sum_{i=2}^{3} \sum_{j=1}^{2} F_{t y i j}, \\
I_{z} \ddot{\psi}+ & 2 I_{z b} \dot{\varphi} \dot{\theta}-\left(I_{b x z}+M_{b} l_{s} h_{s}\right) \ddot{\varphi}-M_{b} l_{s}\left(\ddot{y}+\dot{x} \dot{\psi}-\dot{z}_{b} \dot{\varphi}\right) \\
= & l_{1}\left[\left(F_{t x 11}+F_{t x 12}\right) \sin \delta+\left(F_{t y 11}+F_{t y 12}\right) \cos \delta\right] \\
& -\left(l_{2}-\frac{l_{3}}{2}\right) \sum_{j=1}^{2} F_{t y 2 j}-\left(l_{2}+\frac{l_{3}}{2}\right) \sum_{j=1}^{2} F_{t y 3 j} \\
& +\frac{d_{t 1}}{2}\left[\left(-F_{t x 11}+F_{t x 12}\right) \cos \delta+\left(F_{t y 11}-F_{t y 12}\right) \sin \delta\right] \\
& \\
& \\
& \\
&
\end{aligned}
$$

$$
\begin{aligned}
M_{b}\left(\ddot{z}_{b}-\dot{x} \dot{\theta}+\dot{y} \dot{\varphi}\right)-M_{b} h_{s}\left(\dot{\theta}^{2}+\dot{\varphi}^{2}\right) \\
\quad-M_{b} l_{s} \ddot{\theta}-\left(F_{c 1}+F_{c 2}+F_{c 3}+F_{c 4}\right) \\
\quad+\left(F_{s 11}+F_{s 12}+F_{s 21}+F_{s 22}+F_{s 31}+F_{s 32}\right)=-M_{b} g \\
\left(M_{b} h_{s}^{2}+I_{b x}\right) \ddot{\varphi}-\left(I_{b x z}+M_{b} l_{s} h_{s}\right)(\ddot{\psi}+2 \dot{\varphi} \dot{\theta}) \\
\quad-M_{b} h_{s}\left(\ddot{y}+\dot{x} \dot{\psi}-\dot{z}_{b} \dot{\varphi}\right) \\
\quad+\left(F_{c 2}+F_{c 4}-F_{c 1}-F_{c 3}\right) \frac{d_{c}}{2} \\
\quad+\left(F_{s 11}-F_{s 12}\right) \frac{d_{s 1}}{2}+\left(F_{s 21}-F_{s 22}\right) \frac{d_{s 2}}{2} \\
\quad+\left(F_{s 31}-F_{s 32}\right) \frac{d_{s 3}}{2}
\end{aligned}
$$




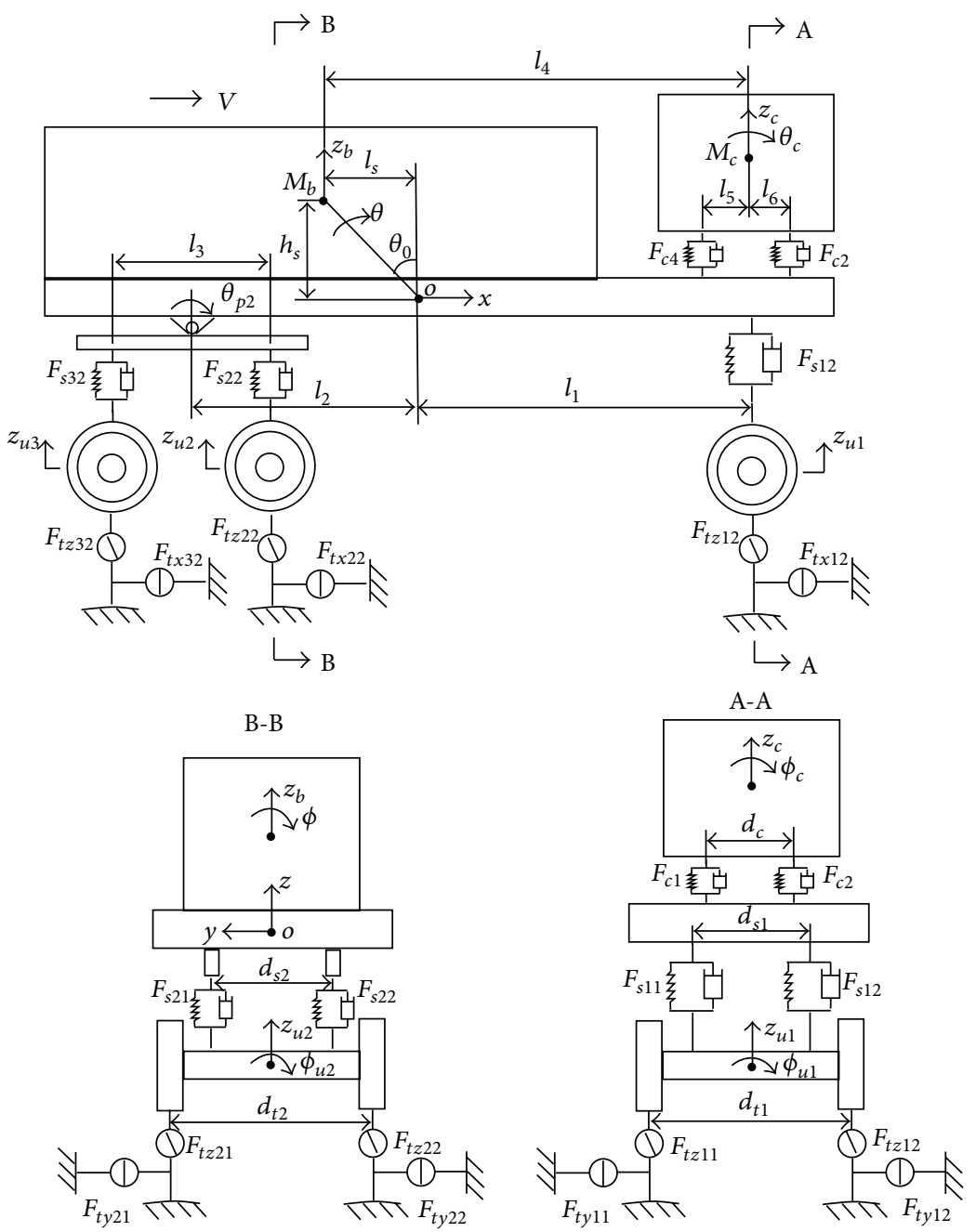

FIgURE 1: Three-directional coupled heavy vehicle model with 23-DOF.

$$
\begin{aligned}
&=\left(z_{b}-z_{t 11}+R_{11}\right)\left(F_{t x 11} \sin \delta+F_{t y 11} \cos \delta\right) \\
&+\left(z_{b}-z_{t 12}+R_{12}\right)\left(F_{t x 12} \sin \delta+F_{t y 12} \cos \delta\right) \\
&+\sum_{i=2}^{3} \sum_{j=1}^{2} F_{t y i j}\left(z_{b}-z_{t i j}+R_{i j}\right), \\
&\left(M_{b} h_{s}^{2}+I_{b y}\right) \ddot{\theta}-M_{b} h_{s} l_{s}\left(\dot{\psi}^{2}+\dot{\theta}^{2}\right) \\
& \quad+M_{b} h_{s}\left(\ddot{x}-\dot{y} \dot{\psi}+\dot{z}_{b} \dot{\theta}\right) \\
& \quad-M_{b} l_{s}\left(\ddot{z}_{b}+g-\dot{x} \dot{\theta}+\dot{y} \dot{\varphi}\right) \\
& \quad+M_{b} l_{s}^{2} \ddot{\theta}+\left(F_{c 1}+F_{c 2}\right)\left(l_{4}+l_{5}\right) \\
& \quad+\left(F_{c 3}+F_{c 4}\right)\left(l_{4}-l_{6}\right) \\
& \quad-\left(F_{s 11}+F_{s 12}\right) l_{1}+\left(F_{s 21}+F_{s 22}+F_{s 31}+F_{s 32}\right) l_{2} \\
&=\left(z_{b}-z_{t 11}+R_{11}\right)\left(F_{t x 11} \cos \delta-F_{t y 11} \sin \delta\right)
\end{aligned}
$$

$$
\begin{aligned}
& +\left(z_{b}-z_{t 12}+R_{12}\right)\left(F_{t x 12} \cos \delta-F_{t y 12} \sin \delta\right) \\
& +\sum_{i=2}^{3} \sum_{j=1}^{2} F_{t x i j}\left(z_{b}-z_{t i j}+R_{i j}\right)
\end{aligned}
$$

where $\delta, T_{z i j}$, and $R_{i j}$ are the steering angle of front wheel, the tire aligning torque, and the tire effective radius, respectively. $F_{c s}(s=1 \sim 4)$ denotes the suspension forces between driver $\mathrm{cab}$ and vehicle body and can be expressed as

$$
\begin{aligned}
F_{c 1}= & K_{c 1}\left(z_{c}-\theta_{c} l_{5}-z_{b}\right. \\
& \left.+\left(\theta-\theta_{0}\right)\left(l_{4}+l_{5}\right)-\frac{\left(\varphi-\varphi_{c}\right) d_{c}}{2}\right) \\
& +C_{c 1}\left(\dot{z}_{c}-\dot{\theta}_{c} l_{5}-\dot{z}_{b}+\dot{\theta}\left(l_{4}+l_{5}\right)-\frac{\left(\dot{\varphi}-\dot{\varphi}_{c}\right) d_{c}}{2}\right),
\end{aligned}
$$




$$
\begin{aligned}
F_{c 2}= & K_{c 2}\left(z_{c}-\theta_{c} l_{5}-z_{b}\right. \\
& \left.+\left(\theta-\theta_{0}\right)\left(l_{4}+l_{5}\right)+\frac{\left(\varphi-\varphi_{c}\right) d_{c}}{2}\right) \\
& +C_{c 2}\left(\dot{z}_{c}-\dot{\theta}_{c} l_{5}-\dot{z}_{b}+\dot{\theta}\left(l_{4}+l_{5}\right)+\frac{\left(\dot{\varphi}-\dot{\varphi}_{c}\right) d_{c}}{2}\right) \\
F_{c 3}= & K_{c 3}\left(z_{c}+\theta_{c} l_{6}-z_{b}\right. \\
& \left.+\left(\theta-\theta_{0}\right)\left(l_{4}-l_{6}\right)-\frac{\left(\varphi-\varphi_{c}\right) d_{c}}{2}\right) \\
& +C_{c 3}\left(\dot{z}_{c}+\dot{\theta}_{c} l_{6}-\dot{z}_{b}+\dot{\theta}\left(l_{4}-l_{6}\right)-\frac{\left(\dot{\varphi}-\dot{\varphi}_{c}\right) d_{c}}{2}\right) \\
& +C_{c 4}\left(\dot{z}_{c}+\dot{\theta}_{c} l_{6}-\dot{z}_{b}+\dot{\theta}\left(l_{4}-l_{6}\right)+\frac{\left(\dot{\varphi}-\dot{\varphi}_{c}\right) d_{c}}{2}\right) \\
F_{c 4}= & K_{c 4}\left(z_{c}+\theta_{c} l_{6}-z_{b}\right. \\
& \left.+\left(\theta-\theta_{0}\right)\left(l_{4}-l_{6}\right)+\frac{\left(\varphi-\varphi_{c}\right) d_{c}}{2}\right)
\end{aligned}
$$

For this heavy-duty vehicle, two hydraulic dampers are fixed on the left and right front suspensions and the tandem balanced suspension does not have any shock absorber. In order to represent the frictional property of leaf spring, the damping forces of tandem balanced suspension are modeled linearly. The suspension forces between middle or rear axle and vehicle body are given by

$F_{s 21}$

$$
\begin{aligned}
= & K_{s 21}\left(z_{b}+\left(\theta-\theta_{0}\right) l_{2}-\frac{\theta_{p 1} l_{3}}{2}-z_{u 2}+\frac{\left(\varphi-\varphi_{u 2}\right) d_{s 2}}{2}\right) \\
& +C_{s 21}\left(\dot{z}_{b}+\dot{\theta} l_{2}-\frac{\dot{\theta}_{p 1} l_{3}}{2}-\dot{z}_{u 2}+\frac{\left(\dot{\varphi}-\dot{\varphi}_{u 2}\right) d_{s 2}}{2}\right),
\end{aligned}
$$

$F_{s 22}$

$$
\begin{aligned}
= & K_{s 22}\left(z_{b}+\left(\theta-\theta_{0}\right) l_{2}-\frac{\theta_{p 2} l_{3}}{2}-z_{u 2}-\frac{\left(\varphi-\varphi_{u 2}\right) d_{s 2}}{2}\right) \\
& +C_{s 22}\left(\dot{z}_{b}+\dot{\theta} l_{2}-\frac{\dot{\theta}_{p 2} l_{3}}{2}-\dot{z}_{u 2}-\frac{\left(\dot{\varphi}-\dot{\varphi}_{u 2}\right) d_{s 2}}{2}\right)
\end{aligned}
$$

$F_{s 31}$

$$
\begin{aligned}
= & K_{s 31}\left(z_{b}+\left(\theta-\theta_{0}\right) l_{2}+\frac{\theta_{p 1} l_{3}}{2}-z_{u 3}+\frac{\left(\varphi-\varphi_{u 3}\right) d_{s 3}}{2}\right) \\
& +C_{s 31}\left(\dot{z}_{b}+\dot{\theta} l_{2}+\frac{\dot{\theta}_{p 1} l_{3}}{2}-\dot{z}_{u 3}+\frac{\left(\dot{\varphi}-\dot{\varphi}_{u 3}\right) d_{s 3}}{2}\right),
\end{aligned}
$$

$$
\begin{aligned}
F_{s 32} & \\
r & K_{s 32}\left(z_{b}+\left(\theta-\theta_{0}\right) l_{2}+\frac{\theta_{p 2} l_{3}}{2}-z_{u 3}-\frac{\left(\varphi-\varphi_{u 3}\right) d_{s 3}}{2}\right) \\
& +C_{s 32}\left(\dot{z}_{b}+\dot{\theta} l_{2}+\frac{\dot{\theta}_{p 2} l_{3}}{2}-\dot{z}_{u 3}-\frac{\left(\dot{\varphi}-\dot{\varphi}_{u 3}\right) d_{s 3}}{2}\right) .
\end{aligned}
$$

Since hydraulic dampers show obvious nonlinearity, many dynamic models for shock absorber have been proposed, among which the fitted model is quite suitable to modeling the ascertained shock absorber but needs a large amount of experimental work $[17,18]$. In this work, the dynamic property of the damper on front suspension is measured by HT-911 testing machine under sinusoidal excitation. Since the inherence frequency of the vehicle body is from $1 \mathrm{~Hz}$ to $2.5 \mathrm{~Hz}$, four excitation frequencies are selected as $1 \mathrm{~Hz}, 1.5 \mathrm{~Hz}, 2 \mathrm{~Hz}$, and $2.5 \mathrm{~Hz}$. Limited by the machine's tonnage, the excitation amplitude is chosen as $10 \mathrm{~mm}$. Figure 2 shows the measured force-velocity curves. Since the hysteresis loops of damping force depend on the excitation frequency and amplitude greatly, the parameters of hysteresis model under random excitations are difficult to identify. Hence, a nonlinear segmented model describing the damper's scheme framework is proposed here,

$$
F_{d}= \begin{cases}F_{01} \operatorname{sgn}\left(v_{d}\right) & v_{d}>v_{\lim 1} \\ C\left(1+\beta \operatorname{sgn}\left(v_{d}\right)\right) v_{d}\left|v_{d}\right|^{n} & v_{\lim 2} \leq v_{d} \leq v_{\lim 1} \\ F_{02} \operatorname{sgn}\left(v_{d}\right) & v_{d}<v_{\lim 2},\end{cases}
$$

where $v_{d}, C, \beta$, and $n$ are the relative velocity of cylinder and plunger, the damping coefficient, the asymmetry ratio, and the exponent, respectively. $F_{01}, F_{02}, v_{\lim 1}$, and $v_{\lim 2}$ are the damping force and relative velocity when the damper reaching saturation in tension or compression process.

Parameters in model (5) fitted to the measured data are $C=30893, \beta=0.56, n=0.16, F_{01}=4119 \mathrm{~N}, F_{02}=726 \mathrm{~N}$, $v_{\lim 1}=0.12 \mathrm{~m} / \mathrm{s}$, and $v_{\lim 2}=0.08 \mathrm{~m} / \mathrm{s}$. The damping force curve obtained from the theoretical damper model is shown as the thick solid line in Figure 2. It can be seen that the presented damping force model is able to describe the scheme framework and saturation property of the damper. Though model (5) neglects the damper's hysteresis characteristics, it is simple and accurate enough for numerical simulation.

Using model (5) to calculate the damping force, the front suspension forces are expressed by

$$
\begin{aligned}
& F_{s 11}=K_{s 11}\left(z_{b}-\left(\theta-\theta_{0}\right) l_{1}-z_{u 1}+\frac{\left(\varphi-\varphi_{u 1}\right) d_{s 1}}{2}\right)+F_{d 11}, \\
& F_{s 12}=K_{s 12}\left(z_{b}-\left(\theta-\theta_{0}\right) l_{1}-z_{u 1}-\frac{\left(\varphi-\varphi_{u 1}\right) d_{s 1}}{2}\right)+F_{d 12},
\end{aligned}
$$

where $F_{d 11}$ and $F_{d 12}$ are the left and right damping force of front suspension. The relative velocities of left and right 


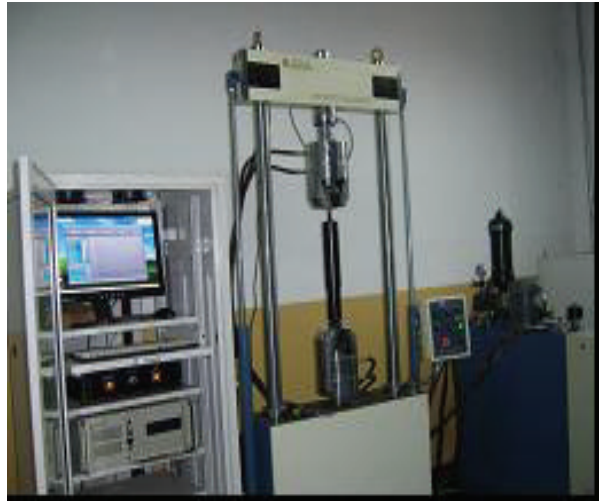

(a)

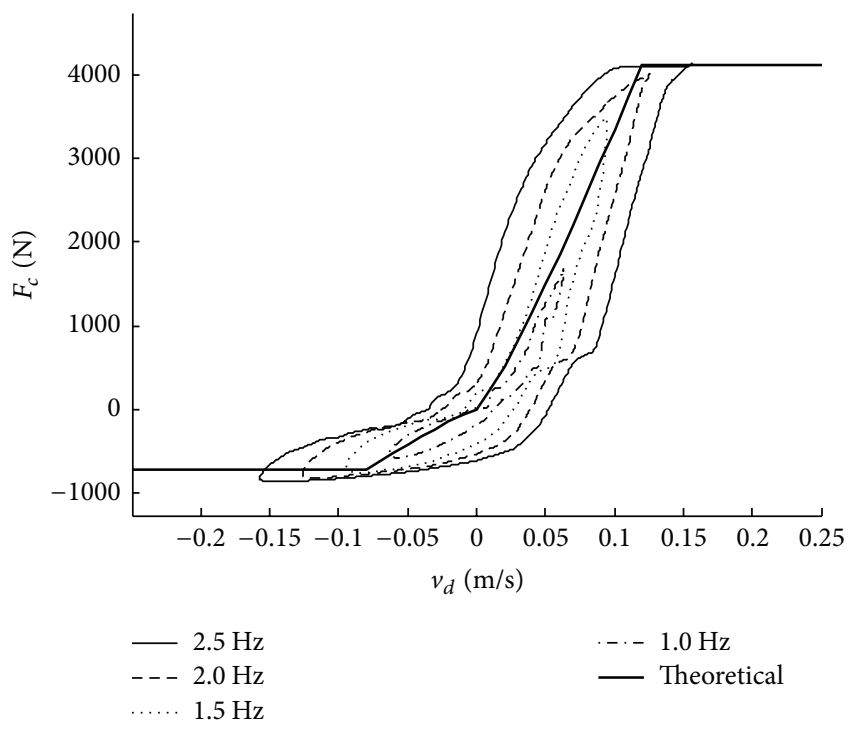

(b)

Figure 2: Dynamic test and modeling of the damper.

damper are obtained by $v_{d 1}=\left(\dot{z}_{b}-\dot{\theta} l_{1}-\dot{z}_{u 1}+\left(\dot{\varphi}-\dot{\varphi}_{u 1}\right) d_{s 1} / 2\right)$ and $v_{d 2}=\left(\dot{z}_{b}-\dot{\theta} l_{1}-\dot{z}_{u 1}-\left(\dot{\varphi}-\dot{\varphi}_{u 1}\right) d_{s 1} / 2\right)$.

The following equations give the balancing pole pitch, the cab vertical, roll and pitch, and the axle vertical and roll movements:

$$
\begin{gathered}
I_{p i} \ddot{\theta}_{p i}+\left(F_{s 3 i}-F_{s 2 i}\right) \frac{l_{3}}{2}=0 \\
M_{c} \ddot{z}_{c}+\left(F_{c 1}+F_{c 2}+F_{c 3}+F_{c 4}\right)=-M_{b} g \\
I_{c x} \ddot{\phi}_{c}+\left(F_{c 1}+F_{c 3}-F_{c 2}-F_{c 4}\right) \frac{d_{c}}{2}=0 \\
I_{c y} \ddot{\theta}_{c}-\left(F_{c 1}+F_{c 2}\right) l_{5}+\left(F_{c 3}+F_{c 4}\right) l_{6}=0 \\
M_{u i} \ddot{z}_{u i}-F_{s i 1}-F_{s i 2}=F_{t z i 1}+F_{t z i 2}-M_{u i} g \\
I_{u i} \ddot{\phi}_{u i}+\left(F_{s i 2}-F_{s i 1}\right) \frac{d_{s i}}{2} \\
=\left(F_{t z i 1}-F_{t z i 2}\right) \frac{d_{t i}}{2}+\left(F_{t y i 1}+F_{t y i 2}\right) R_{i} .
\end{gathered}
$$

2.2. Tire Model. The vertical square nonlinear tire model [19] is given as

$$
\begin{aligned}
F_{t z i j}= & K_{t i j}\left(z_{0 i j}-z_{t i j}\right)+C_{t i j}\left(\dot{z}_{0 i j}-\dot{z}_{t i j}\right) \\
& +\varepsilon K_{t i j}\left(z_{0 i j}-z_{t i j}\right)^{2},
\end{aligned}
$$

where $K_{t i j}$ and $C_{t i j}$ are the linear tire vertical stiffness and damping coefficient, respectively. $\varepsilon$ and $z_{0 i j}$ are the square nonlinear stiffness coefficient and road unevenness, respectively. From the axle vertical and roll displacements, the vertical tire displacements $z_{t i j}$ can be gained:

$$
z_{t i 1}=z_{u i}+\phi_{u i} \frac{d_{s i}}{2}, \quad z_{t i 2}=z_{u i}-\phi_{u i} \frac{d_{s i}}{2} .
$$

Here, subscript $i$ stands for the front, middle, or rear axle $(i=$ $1-3) . j$ stands for the left or right wheel $(j=1-2)$.

Based on Gim tire model [20, 21], the lateral and longitudinal tire forces and aligning torque are described by

$$
\begin{gathered}
F_{t x i j} \\
= \begin{cases}K_{x i j} S_{s i j} l_{n i j}^{2}+\mu_{x i j} F_{t z i j}\left(1-3 l_{n i j}^{2}+2 l_{n i j}^{3}\right) & S_{s i j}<S_{s i j} \\
\mu_{x i j} F_{t z i j} & S_{s i j} \geq S_{s c i j},\end{cases} \\
F_{t y i j} \\
= \begin{cases}K_{\alpha i j} S_{\alpha i j} l_{n i j}^{2}+\mu_{y i j} F_{t z i j}\left(1-3 l_{n i j}^{2}+2 l_{n i j}^{3}\right) & S_{\alpha i j}<S_{\alpha c i j} \\
\mu_{y i j} F_{t z i j} & S_{\alpha i j}<S_{\alpha c i j},\end{cases} \\
T_{z i j}=F_{y i j} D_{x i j}-F_{x i j}\left(D_{y i j}+y_{b i j}\right),
\end{gathered}
$$

where

$$
S_{s i j}=\frac{\left(V_{x}-\omega_{i j} R_{i j}\right)}{V_{x}},
$$

$$
S_{\alpha i j}= \begin{cases}\left|\tan \alpha_{i j}\right| & \text { brake } \\ \left(1-\left|S_{s i j}\right|\right)\left|\tan \alpha_{i j}\right| & \text { driving }\end{cases}
$$

are the longitudinal and lateral wheel slip ratio. $S_{s \alpha i j}=$ $\sqrt{S_{s i j}^{2}+S_{\alpha i j}^{2}}, l_{n i j}=1-S_{n i j}, S_{n i j}=\sqrt{\left(K_{x i j} S_{s i j}\right)^{2}+\left(K_{\alpha i j} S_{\alpha i j}\right)^{2}} /$ 
$\left(3 \mu_{i j} F_{t z i j}\right), S_{s c i j}=3 \mu_{i j} F_{z i j} / K_{x i j}$, and $S_{\alpha c i j}=K_{x i j} \sqrt{S_{s c i j}^{2}-S_{s i j}^{2}} /$ $K_{\alpha i j}$ are tire parameters related to slip ratio. $\mu_{i j}=\mu_{0}(1-(1-$ $\left.\left.\mu_{1} / \mu_{0}\right) S_{s \alpha i j} / S_{1}\right), \mu_{x i j}=\mu_{i j} S_{s i j} / S_{s \alpha i j}$, and $\mu_{y i j}=\mu_{i j} S_{\alpha i j} / S_{s \alpha i j}$ are road adhesion coefficients. $V_{x}, K_{x i j}$, and $K_{\alpha i j}$ are the vehicle running speed, and tire longitudinal and lateral stiffness, respectively. The wheel rotating rate $\omega_{i j}$ is given by

$$
I_{i j} \dot{\omega}_{i j}=T_{s i j}-T_{b i j}-R_{i j} \cdot F_{t x i j}
$$

where $T_{s i j}$ and $T_{b i j}(i=1 \sim 3, j=1 \sim 2)$ are the driving torque and braking torque of six wheels.

2.3. Driver Model. According to Guo's preview of optimal curvature driver model $[3,4]$, the optimal front steering angle is expressed by

$$
\delta_{p}=\frac{2 L}{d^{2}}[f(t+T)-y(t)-T \dot{y}(t)],
$$

where $d, T$, and $L$ are the preview distance, preview time, and wheelbase, respectively. $f(t+T)$ is the lateral position of the desired route at preview point and $y(t)$ is the vehicle lateral position at current time.

The above model is very simple and suitable to simulate lateral dynamics of vehicle running at a constant speed. However, it neglects the effect of time delay, and the desired route function $f(t)$ needs to be computed according to vehicle speed and trajectory before simulation.

Legouis' driver model with nonlinear time delay [6-8] calculates the front steering angle by

$$
\delta_{p}=-K\left[y_{N}\left(t-T_{r}\right)+\frac{d}{U} \dot{y}_{N}\left(t-T_{r}\right)\right],
$$

where $K, T_{r}$, and $U$ are feedback gain, time delay, and vehicle running speed, respectively. $y_{N}\left(t-T_{r}\right)$ and $y_{N}\left(t-T_{r}\right)+$ $(d / U) \dot{y}_{N}\left(t-T_{r}\right)$ are the lateral position of vehicle gravity center and preview point in the inertial frames, respectively. This model introduced time delay and calculated position deviation between vehicle and desired route in the inertial frames. However, the feedback gain in Legouis' driver model is a constant and cannot be obtained by vehicle parameters. The ideal route function is not included in the model because the straight-line driving condition is researched. In addition, the preview point is gained from vehicle gravity center and neglects the difference of longitudinal distance and yaw angle between vehicle gravity center and driver position.

By combining the above two models, a modified driver model is proposed here as shown in Figure 3. The front wheel steering angle is given by

$$
\begin{array}{r}
\delta_{p}(t)=\frac{2 L}{d^{2}}\left[R Y_{d}\left(t-T_{r}\right)-Y_{d}\left(t-T_{r}\right)\right] \\
\left|R Y_{d}\left(t-T_{r}\right)-Y_{d}\left(t-T_{r}\right)\right|>e_{c r} \\
\delta_{p}(t)=\delta_{p}(t-d t) \\
\left|R Y_{d}\left(t-T_{r}\right)-Y_{d}\left(t-T_{r}\right)\right| \leq e_{c r},
\end{array}
$$

where $R Y_{d}, Y_{d}, e_{c r}$, and $d t$ are the required lateral position and real lateral displacement of the preview point in the ground

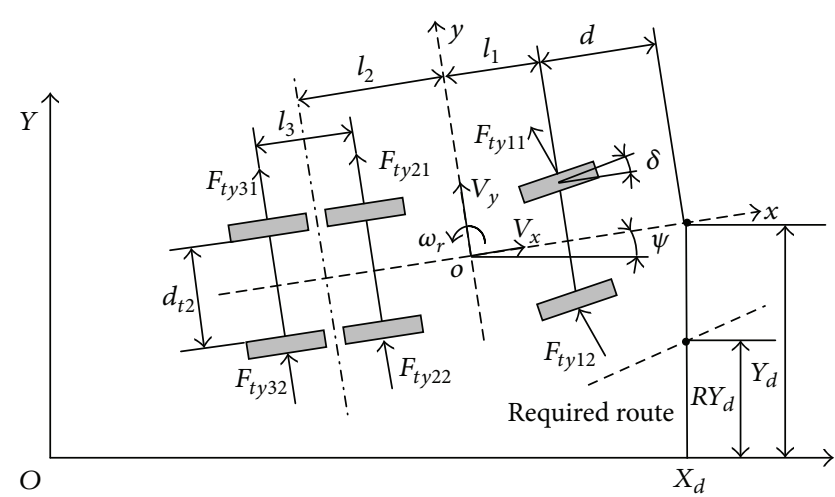

FIgURE 3: The new driver control model with nonlinear time delay.

coordinate system, the permit position error, and the integration time step, respectively. For three-axle vehicle, the parameter $L$ in (15) is the distance between front wheel and center of balance suspension and is expressed by $L=l_{1}+l_{2}$.

This modified model has a feedback gain $2 L / d^{2}$ that is defined by wheelbase and preview distance. It can be noticed that a big wheelbase or a small preview distance will lead to a big gain. This statement is well understood, because drivers feel it difficult to control the vehicle direction in the case of big wheelbase or small preview distance, so they have to increase the intervention of steering angle.

The displacement of the preview point in the ground coordinate system is

$$
\begin{aligned}
& X_{d}=X(t)+l_{1} \cos \psi+\frac{d}{U}\left(\dot{X}-l_{1} \dot{\psi} \sin \psi\right) \\
& Y_{d}=Y(t)+l_{1} \sin \psi+\frac{d}{U}\left(\dot{Y}+l_{1} \dot{\psi} \cos \psi\right),
\end{aligned}
$$

where $X(t), Y(t)$, and $\psi$ are displacements and heading angle of vehicle gravity center in the ground coordinate system. It should be noted that the preview point lies in $d$ meter ahead of driver seat not vehicle gravity center. According to $X_{d}$ and the required route function, the required lateral position $R Y_{d}$ is easily obtained. Substituting $R Y_{d}$ and $Y_{d}$ into (15) and introducing time delay, the front wheel angle can be obtained. It should be noted that the modified driver model depends on the vehicle longitudinal speed as strongly as Legouis' driver model.

The displacements and velocities in vehicle coordinate system $(x, y, z)$ can be gained from vehicle model and transferred to the ground coordinate system $(X, Y, Z)$ by the following relation:

$$
\begin{aligned}
& \dot{X}=V_{x} \cos \psi-V_{y} \sin \psi, \\
& \dot{Y}=V_{x} \sin \psi+V_{y} \cos \psi .
\end{aligned}
$$

Finally, the vehicle model, tire model, and driver model are coupled into the driver-vehicle closed-loop system. The longitudinal slip ratios of six wheels are calculated in realtime with vehicle responses as input. The front wheel steering angle is obtained by the modified driver model and fed back 


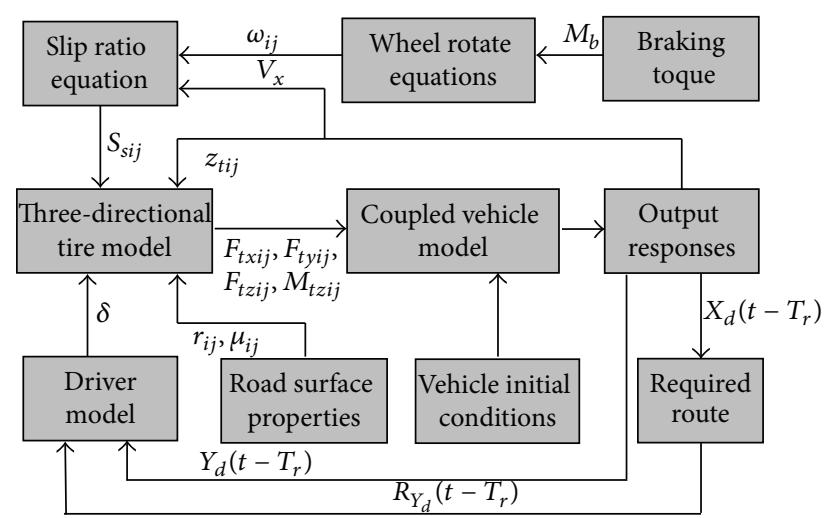

FIgURE 4: The driver-heavy-vehicle closed-loop model.

to the tire model. Then the vertical, longitudinal, and lateral tire forces are calculated by the tire model and input into the vehicle model to gain vehicle responses and positions in next time step. The simulation process of this drivervehicle closed-loop system is shown in Figure 4. Due to the time variability, nonlinearity, and high-dimensional property of this system, the closed-loop system equations are solved numerically by the quick integration method [22] and the Runge-Kutta method of order four.

\section{Model Evaluation}

In order to verify the presented TCLP vehicle model and the new driver model, simulation results of this drivervehicle closed-loop system are obtained using different vehicle models or driver models. During simulation, the vehicle parameters are chosen for a DFL1250A9 truck manufactured by Dongfeng Motor Group Company Limited [23-25] and the B-class road roughness is selected referring to [26]:

$$
\begin{gathered}
M_{c}=1115 \mathrm{~kg}, \quad M_{b}=6198 \mathrm{~kg}, \quad M=10841 \mathrm{~kg}, \\
I_{z}=136 \times 10^{3} \mathrm{~kg} \mathrm{~m}^{2}, \quad l_{1}=3.64 \mathrm{~m}, \quad l_{2}=2.71 \mathrm{~m}, \\
l_{3}=1.3 \mathrm{~m}, \quad l_{4}=3.88 \mathrm{~m}, \quad l_{5}=1.2 \mathrm{~m}, \\
l_{6}=1.0 \mathrm{~m}, \quad L_{s}=0.266 \mathrm{~m}, \quad H_{s}=0.43 \mathrm{~m}, \\
K_{c 1}=K_{c 2}=74.9 \mathrm{kN} / \mathrm{m}, \quad K_{c 3}=K_{c 4}=44.6 \mathrm{kN} / \mathrm{m}, \\
C_{c 1}=C_{c 2}=1985 \mathrm{~N} \cdot \mathrm{s} / \mathrm{m}, \\
C_{c 3}=C_{c 4}=1185 \mathrm{~N} \cdot \mathrm{s} / \mathrm{m}, \\
K_{s 11}=K_{s 12}=251.38 \mathrm{kN} / \mathrm{m}, \\
C_{s 11}=C_{s 12}=40 \mathrm{kN} \cdot \mathrm{s} / \mathrm{m}, \\
K_{t 11}=K_{t 12}=1100 \mathrm{kN} / \mathrm{m}, \\
C_{t 11}=C_{t 12}=3500 \mathrm{~N} \cdot \mathrm{s} / \mathrm{m}, \\
K_{x 11}=K_{x 12}=186.9 \mathrm{kN} / \mathrm{m}, \\
K_{\alpha 11}=K_{\alpha 12}=227.3 \mathrm{kN} / \mathrm{m},
\end{gathered}
$$

$$
\begin{array}{r}
K_{s i j}=997.5 \mathrm{kN} / \mathrm{m}, \quad C_{s i j}=4000 \mathrm{~N} \cdot \mathrm{s} / \mathrm{m}, \\
K_{t i j}=2200 \mathrm{kN} / \mathrm{m}, \quad C_{t i j}=6300 \mathrm{~N} \cdot \mathrm{s} / \mathrm{m}, \\
K_{x i j}=373.8 \mathrm{kN} / \mathrm{m}, \quad K_{\alpha i j}=454.6 \mathrm{kN} / \mathrm{m} \\
(i=2 \sim 3, j=1 \sim 2), \\
\varepsilon=0.1, \quad d_{t 1}=d_{t 2}=1.9 \mathrm{~m}, \quad R=0.42 \mathrm{~m}, \\
\mu_{0}=0.01, \quad \mu_{1}=0.9, \quad S_{1}=0.15, \\
d=10 \mathrm{~m}, \quad T_{r}=0.1 \mathrm{~s}, \quad e_{r}=0.2 \mathrm{~m} .
\end{array}
$$

The parameters of double-lane change route for the heavy-duty vehicle are chosen referring to $[27,28]$ and shown in Figure 5.

3.1. Comparison with the Handling Stability Vehicle Model. A traditional two-degree of freedom (2DOF) handling stability vehicle model for a three-axle heavy vehicle is set up which considers only the lateral and yaw motion [29]. The ordinary differential equations of motion of this $2 \mathrm{DOF}$ model may be expressed by

$$
m\left(\dot{V}_{y}+V_{x} \omega_{r}\right)=\sum_{i=1}^{6}\left[F_{\alpha i} \cos \left(\delta_{i}\right)\right]
$$

$$
I_{z} \dot{\omega}_{r}=\sum_{i=1}^{6}\left[F_{\alpha i} \cos \left(\delta_{i}\right) l_{x i}+F_{\alpha i} \sin \left(\delta_{i}\right) l_{y i}+M_{z i}\right]
$$

where $m, I_{z}, V_{x}, V_{y}$, and $\omega_{r}$ are vehicle mass, vehicle inertia around $z$ axial, and longitudinal, lateral, and yaw rate of the vehicle, respectively. $\delta_{i}, F_{\alpha i}$, and $M_{z i}$ are steering angle, lateral tire force, and self-aligning torque of wheels, respectively. $l_{x i}$ and $l_{y i}$ are the distance from wheel center to vehicle gravity center in longitudinal and lateral direction, respectively.

The double-lane change responses of this TCLP model and the traditional 2DOF model at an entrance speed of $60 \mathrm{~km} / \mathrm{h}$ are simulated, respectively, and compared in Figure 6. It can be seen from Figure 6 that the results of these two models are very consistent in magnitude and trends. Hence, the two vehicle models verify each other. The TCLP model has a worse path-following ability than the $2 \mathrm{DOF}$ model and the vehicle running speed of TCLP model fluctuates randomly. The yaw rate and lateral acceleration obtained from TCLP model is bigger than that from 2DOF model. The reason for these differences between two models is that the TCLP vehicle model considers B-class road roughness and the coupled effect of roll, vertical, longitudinal, and pitch motion on yaw and lateral motion, while the 2DOF model neglects them.

3.2. Comparison with the Linear Vehicle Model. When the nonlinearity of front suspension damper and tire force is neglected, as shown in Figure 7, the vehicle responses become smaller and the tracking performance is better. Thus, the linear vehicle model may predict more conservative results. 


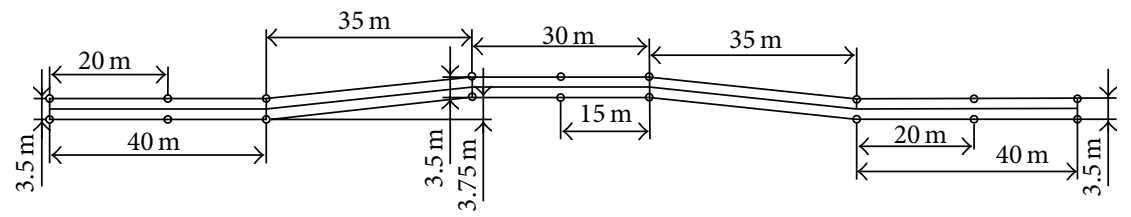

FIGURE 5: The lane change route for the heavy-duty vehicle.
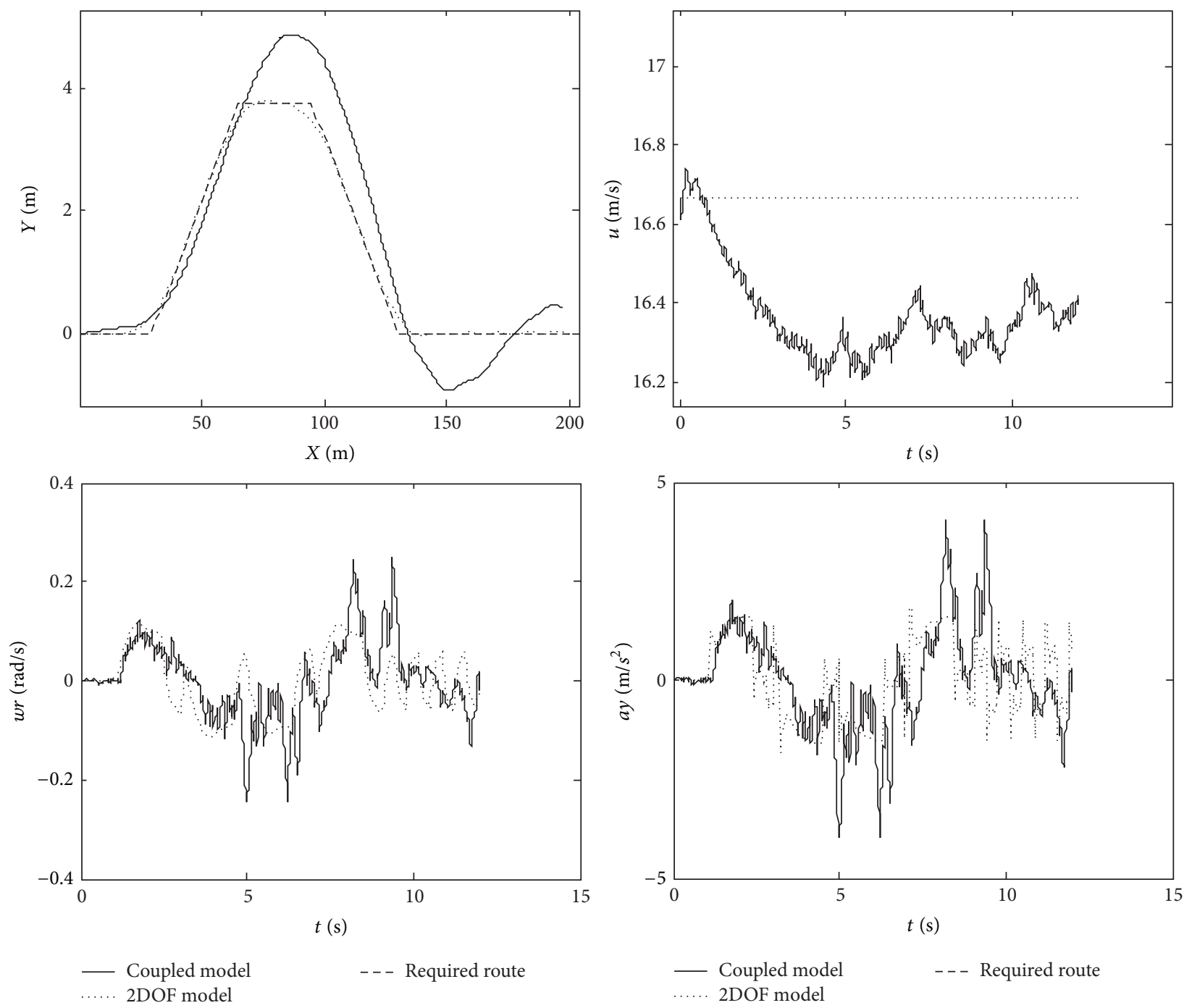

Figure 6: Double-lane change responses of TCLP model and 2DOF model at $60 \mathrm{~km} / \mathrm{h}$.

In the meantime, it is found that the difference between the linear and nonlinear vehicle models in the maneuver of lane change is much greater than that in the maneuver of driving straight. The lateral load transfer, yaw motion and lateral motion while lane change destabilizes the vehicle and consequently aggravates other vehicle motions due to couple effect. In addition, by simulating responses at different entrance speeds, we found that the difference between the linear and nonlinear vehicle models becomes greater with the rise of vehicle speed. Therefore, the nonlinear vehicle model should be used so as to simulate vehicle dynamics accurately, especially in lane change maneuver or high speed driving condition.

3.3. Comparison with Test Data. During double-lane change test, an empty loaded DFL1250A9 truck was selected to run at $30 \mathrm{~km} / \mathrm{h}$ speed. A three-axis piezoelectric accelerometer (frequency range: from $1 \mathrm{~Hz}$ to $500 \mathrm{~Hz}$ ) and a gyro (measuring range: $\pm 50 \mathrm{deg} / \mathrm{s}$ ) were placed at the center of gravity of whole vehicle, and a cable displacement sensor was placed at front wheel to measure front wheel steering angle, as shown in Figure 8. The measured signals were amplified by 

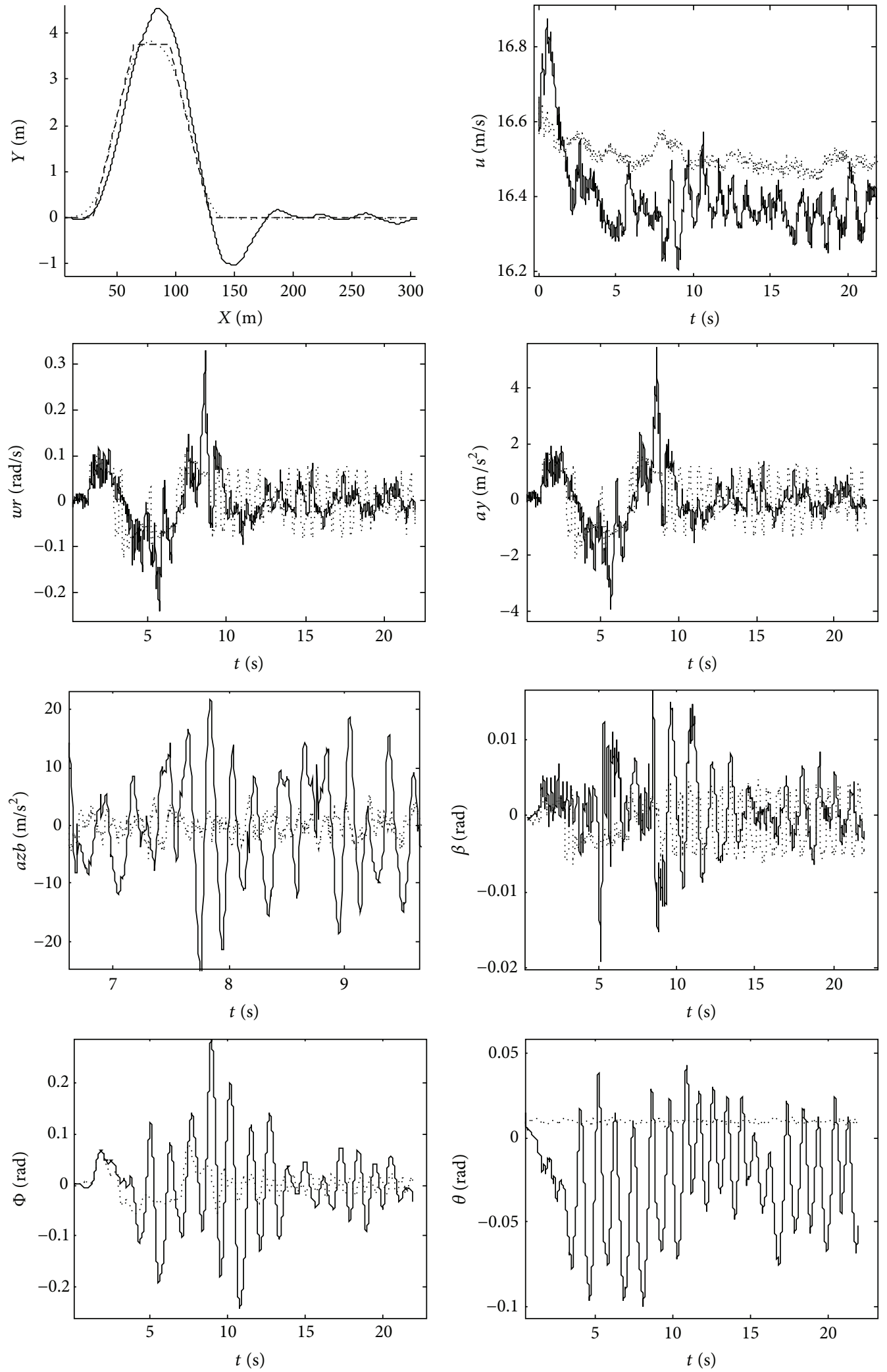

— Nonlinear

- - - Requied route Linear

- Nonlinear

- - - Requied route

FIgURE 7: The double-lane change responses of the linear and nonlinear TCLP model at $60 \mathrm{~km} / \mathrm{h}$. 

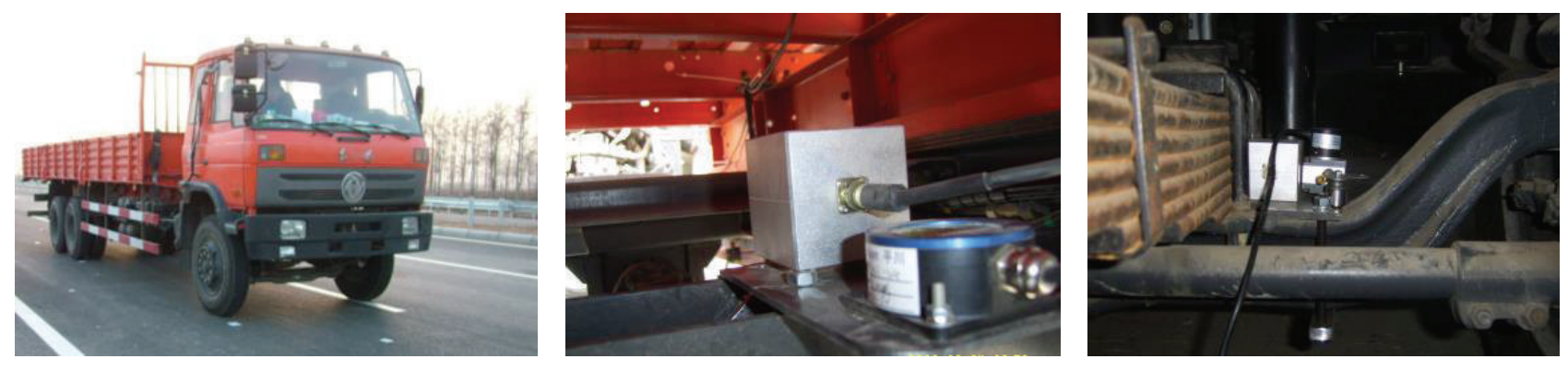

Figure 8: Vehicle and sensors in field test.

TABLE 1: Vehicle responses obtained from three driver models.

\begin{tabular}{|c|c|c|c|c|c|c|c|}
\hline \multirow{2}{*}{ Vehicle speed } & \multirow{2}{*}{ Driver model } & \multicolumn{6}{|c|}{ RMS value of vehicle responses } \\
\hline & & $u$ & $w r$ & ay & $a z b$ & fi & xita \\
\hline \multirow{3}{*}{$20 \mathrm{~km} / \mathrm{h}$} & Modified & 19.6664 & 0.0275 & 0.1502 & 8.7509 & 0.0761 & 0.0881 \\
\hline & Guo & 19.4814 & 0.0282 & 0.1521 & 8.8660 & 0.1040 & 0.0907 \\
\hline & Legouis & 19.6096 & 0.0290 & 0.1577 & 8.2941 & 0.1132 & 0.0981 \\
\hline \multirow{3}{*}{$40 \mathrm{~km} / \mathrm{h}$} & Modified & 39.1248 & 0.0335 & 0.3637 & 7.6438 & 0.0538 & 0.0512 \\
\hline & Guo & 38.9585 & 0.0384 & 0.4153 & 8.2067 & 0.0816 & 0.0648 \\
\hline & Legouis & 39.0766 & 0.0418 & 0.4525 & 7.2862 & 0.0932 & 0.0711 \\
\hline \multirow{3}{*}{$60 \mathrm{~km} / \mathrm{h}$} & Modified & 58.5076 & 0.0562 & 0.9101 & 8.5539 & 0.0763 & 0.0521 \\
\hline & Guo & 58.3891 & 0.0724 & 1.1655 & 8.6102 & 0.1141 & 0.0496 \\
\hline & Legouis & 58.4330 & 0.0707 & 1.1430 & 7.8777 & 0.1158 & 0.0438 \\
\hline \multirow{3}{*}{$80 \mathrm{~km} / \mathrm{h}$} & Modified & 77.8115 & 0.1247 & 2.6747 & 7.7705 & 0.1033 & 0.0377 \\
\hline & Guo & 77.7521 & 0.1194 & 2.5606 & 9.5193 & 0.1140 & 0.0552 \\
\hline & Legouis & 77.5487 & 0.2115 & 4.4610 & 9.3090 & 0.6380 & 0.0522 \\
\hline
\end{tabular}

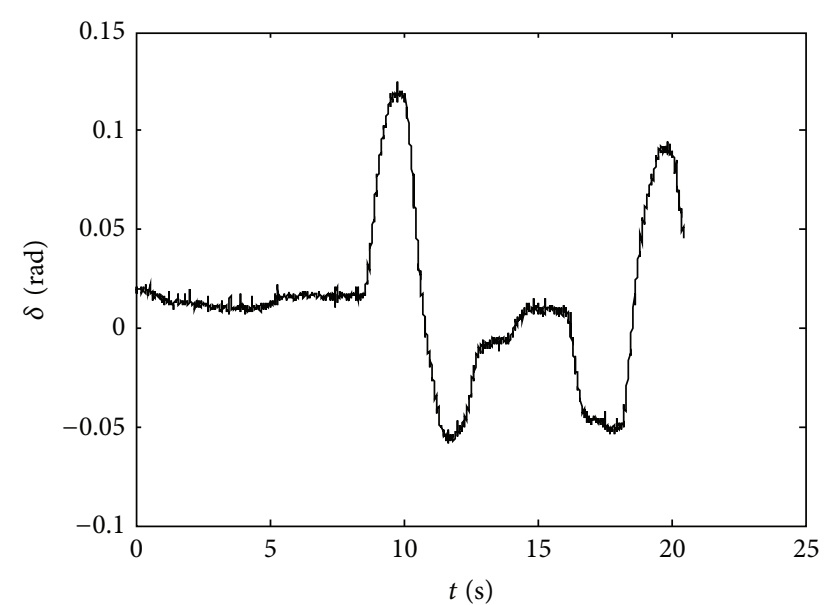

FIgURE 9: Front wheel steering angle in field test.

a multichannel charge amplifier (YE5853A) and converted to digital signals by an intelligent acquisition and processing analyzer (INV360DF). The sampling frequency was $200 \mathrm{~Hz}$.

Figure 9 gives the experimental time history of front wheel steering angle. Using this measured front wheel steering angle as input, the yaw rate and lateral acceleration are calculated from TCLP model, 2DOF model, and linear model, respectively. These simulation results are compared with the test results, as shown in Figure 10. It is obvious that the simulation results of TCLP model are most consistent with the results of field test. Due to neglecting of the threedirectional coupling effects of vehicle motions or nonlinearity of suspension and tire, the time histories of yaw rate obtained from 2DOF model and linear model are too smooth, and the lateral accelerations of 2DOF model and linear model are smaller than the test results. Thus, the verification of this proposed TCLP model is verified.

3.4. Comparison with Other Driver Models. Using the proposed modified driver model, the optimal curvature model by Guo, and nonlinear time delay driver model by Legouis, the trajectories of vehicle gravity center during double-lane change maneuver at four entrance speeds of $20,40,60$, and $80 \mathrm{~km} / \mathrm{h}$ are simulated, respectively, as shown in Figure 11 . Table 1 lists the root mean square (RMS) value of vehicle responses in six directions at different speeds applying these three driver models. As shown in Figure 11, it is obvious that the tracking performance of the modified driver model is superior to the other two driver models at different entrance speeds. It is also found from Figure 11 that though an overshoot of the new model at a vehicle speed of $80 \mathrm{~km} / \mathrm{h}$ exists in $X=[150,180] \mathrm{m}$, the results of the other two models diverge when the vehicle arrives at $X=200 \mathrm{~m}$ while the result of the new model is stable. From Table 1 we can see that the real vehicle speed of the modified driver model is the 

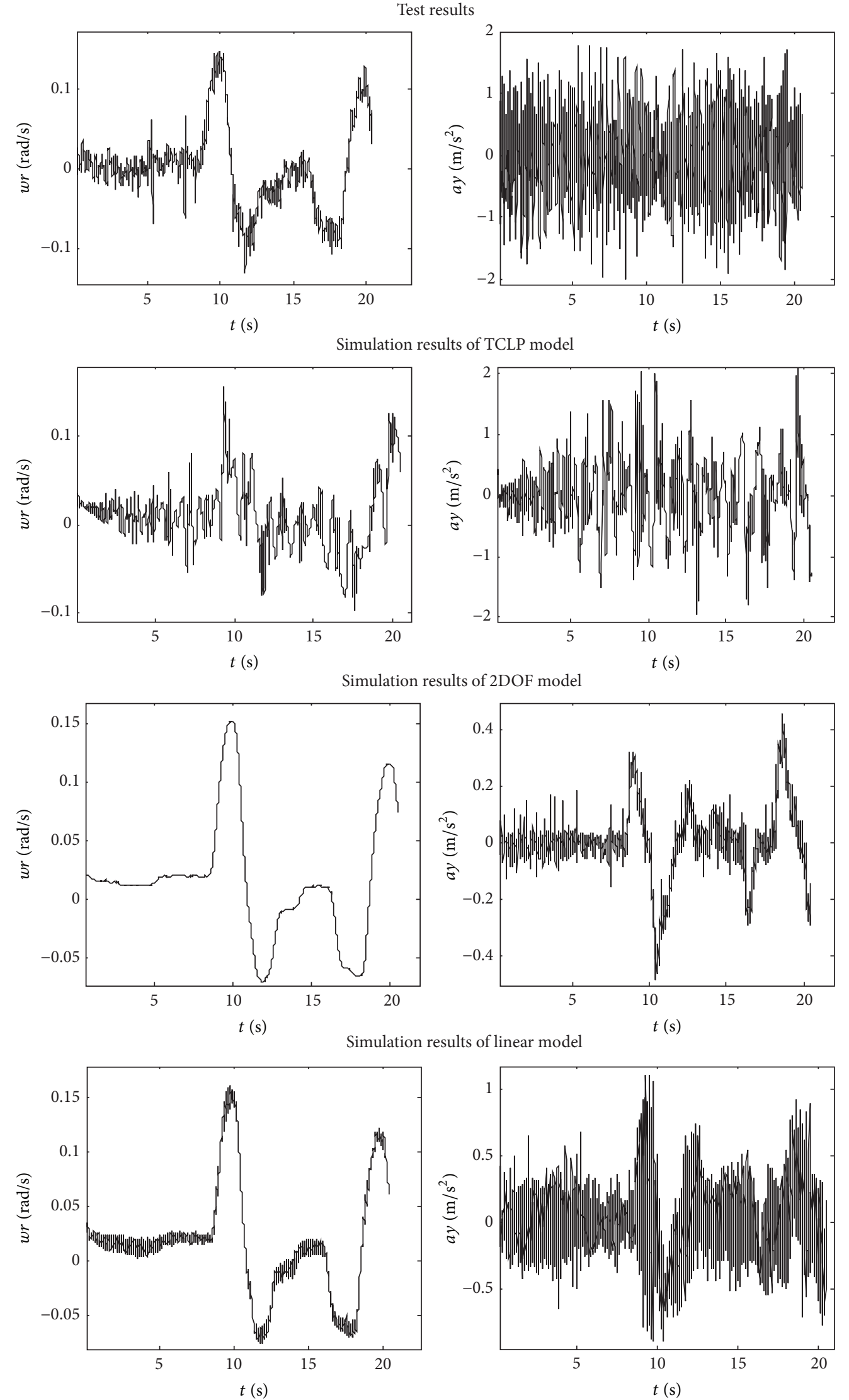

FIGURE 10: Comparison of simulation and test results. 


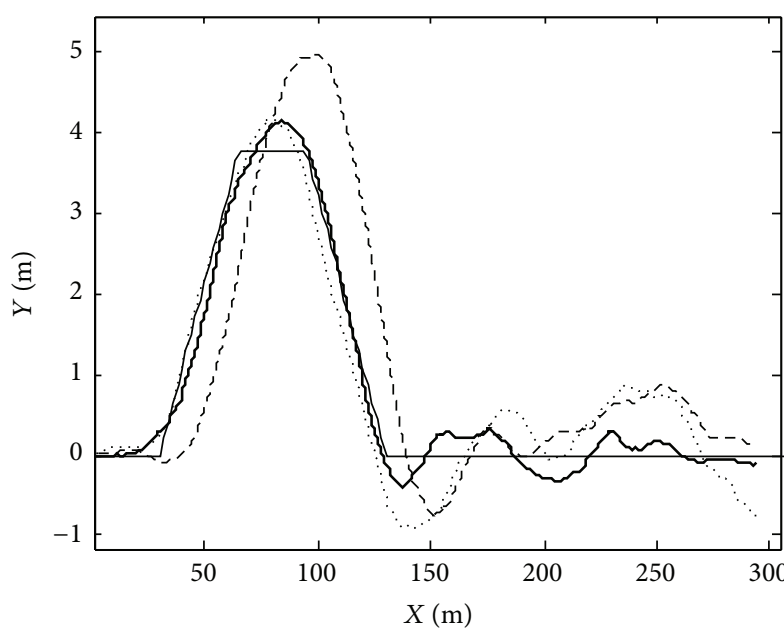

(a) $20 \mathrm{~km} / \mathrm{h}$

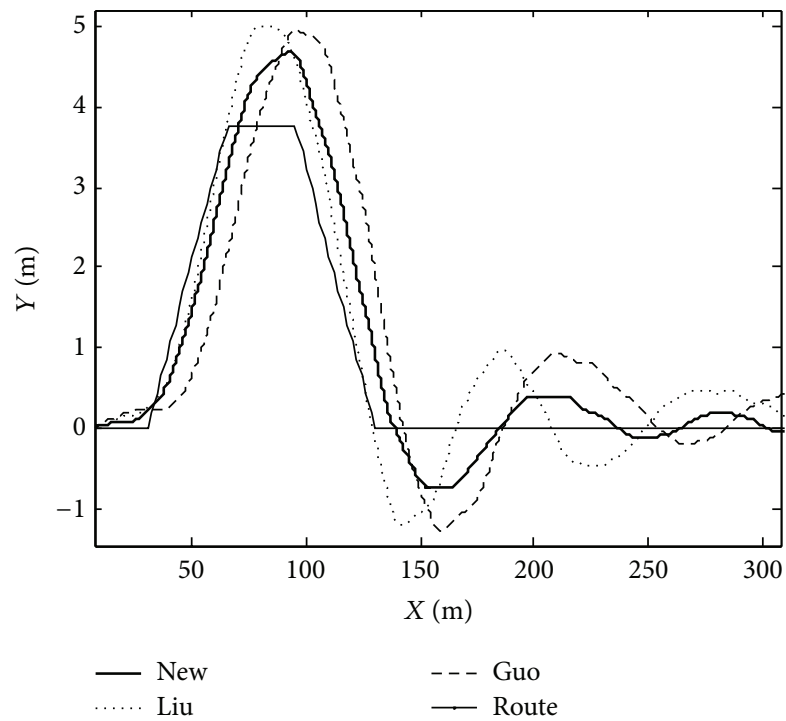

(c) $60 \mathrm{~km} / \mathrm{h}$

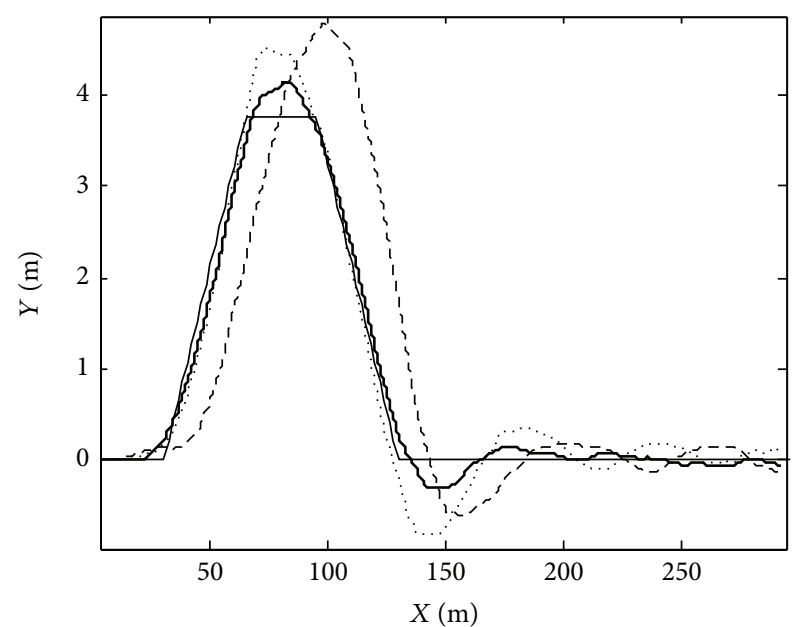

(b) $40 \mathrm{~km} / \mathrm{h}$

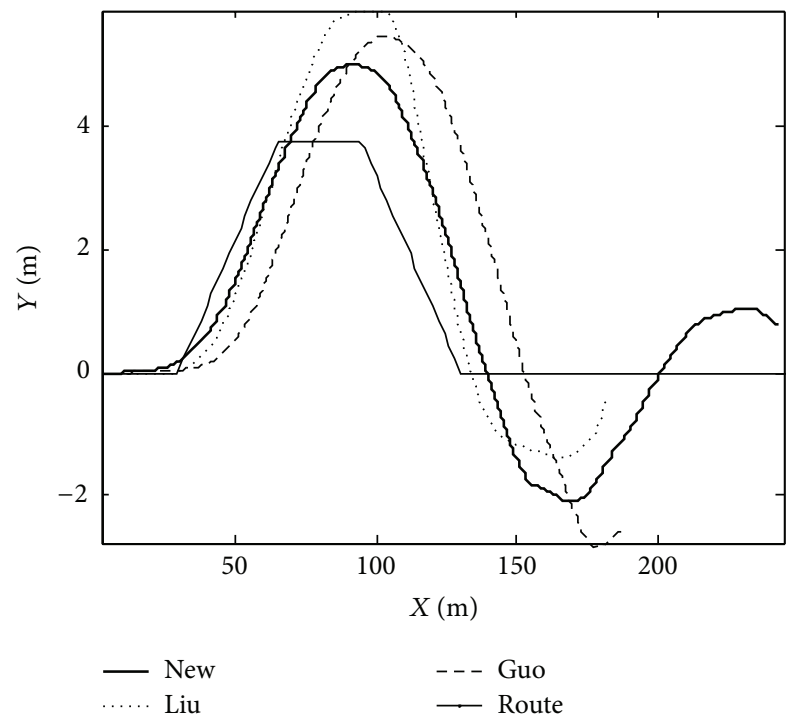

(d) $80 \mathrm{~km} / \mathrm{h}$

FIgURE 11: Comparison of modified driver model with other driver models at different speeds.

closest to the assumed speed, and the modified driver model has smaller responses except for vertical vibration and better stability than the other models. Though the modified driver model obtains greater vertical vehicle acceleration and worse ride comfort than Legouis's model at speeds lower than $60 \mathrm{~km} / \mathrm{h}$, the new driver model can give the vehicle better path-following ability and handling stability.

\section{Effects of Driver Model Parameters on Full Vehicle Dynamics and Stability}

The important parameters in driver model include vehicle running speed, time delay, preview distance, and permit position error, which decide the steering control effect and vehicle dynamics. During the same driving maneuver, the skilled drivers may use higher vehicle speed, longer preview distance, shorter time delay, and larger permit position error than the new drivers. The match of these four driver parameters also influences the vehicle dynamics. Recently Pauwelussen [30] researched the dependencies of driver steering control parameters on vehicle lateral properties and path keeping and gives some useful conclusions. This work focuses on the effects of driver model parameters on both path keeping and full vehicle dynamics, such as vehicle handling stability, ride comfort, and roll stability.

Since the vehicle lateral displacement is randomly caused by road roughness excitations and the lateral position deviation is always changing during lane change maneuvers, a statistic index is introduced to evaluate the vehicle's pathfollowing ability globally, which is formulated by

$$
\text { Route error }=\sqrt{\frac{\sum\left(R Y_{d}(t)-Y_{d}(t)\right)^{2}}{N}},
$$



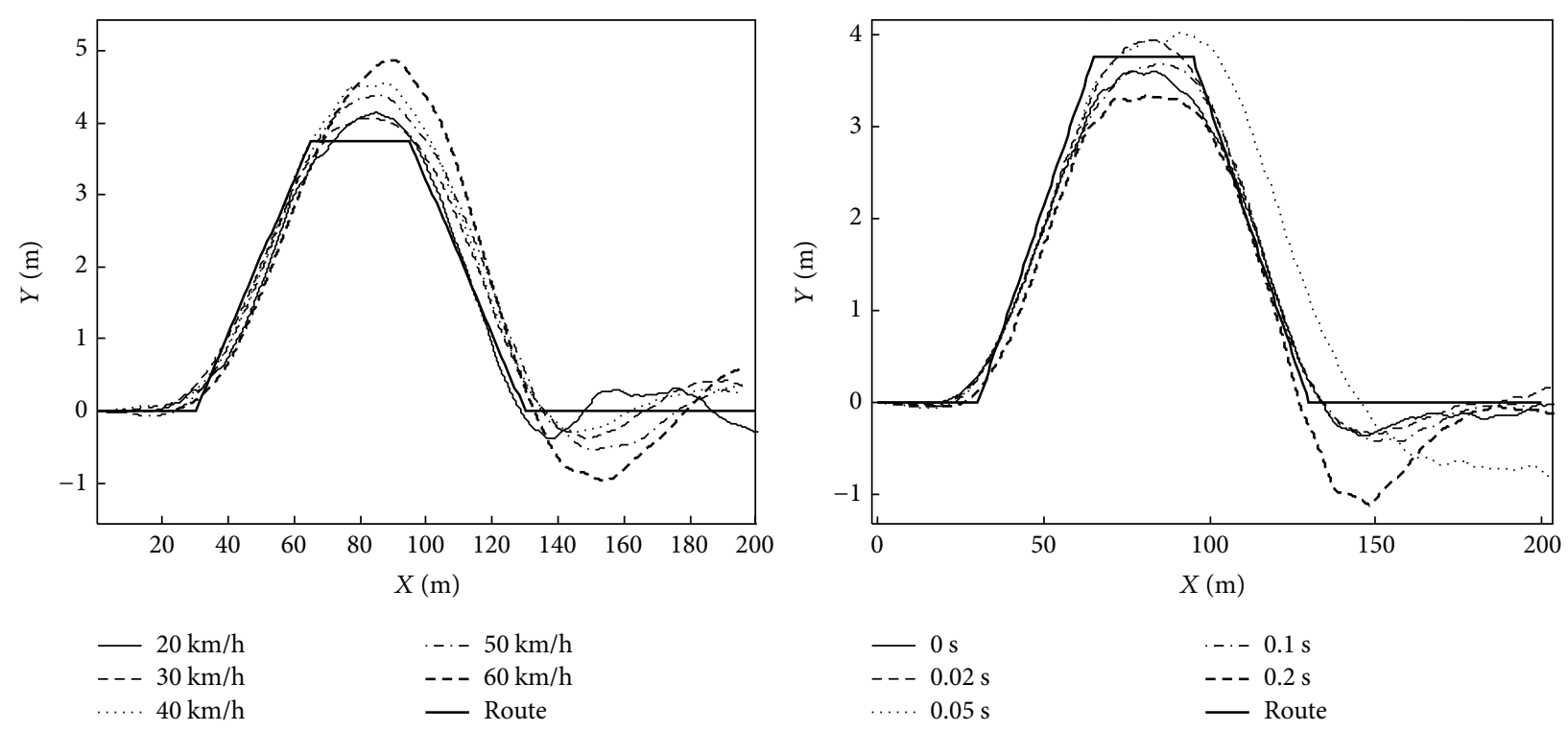

FIGURE 12: Routes of vehicle under different speed or time delay.

where $N$ is the total number of data points. $R Y_{d}$ and $Y_{d}$ are the required lateral position and real lateral displacement of the preview point in the ground coordinate system.

When a vehicle is undergoing a lane change, its steering stability and roll stability are vital problems. The pathfollowing error, lateral acceleration, and yaw rate can be used to evaluate the steering stability. The roll angle can be used to evaluate the roll stability. Being proportional to the rollover index LTR (lateral-load transfer rate), the lateral acceleration is also able to reflect the vehicle roll stability [31]. In addition, the vertical acceleration and pitch angle are simulated so as to research the whole-body dynamics in the vehicle. Using these evaluation indexes, the effects of parameters on steering stability, roll stability, and riding comfort are discussed in detail.

Figure 12 shows the vehicle trajectories under different initial vehicle speeds or driver time delays. The effects of vehicle speed and driver time delay on full vehicle dynamics and stability are shown in Figure 13. As we can see from Figures 12 and 13, a higher speed or a longer time delay will lead to a greater path-following error. However, low speed $(20 \mathrm{~km} / \mathrm{h})$ and longtime delay $(0.35 \mathrm{~s})$ may enlarge the pathfollowing error. With the rise of vehicle speed, the vertical acceleration, lateral acceleration, yaw rate, and roll angle increase, while the pitch angle decreases. Rise of time delay causes the increase of lateral acceleration, yaw rate, and roll angle but hardly changes the vertical acceleration and pitch angle. As for the effects of vehicle speed and driver time delay on full vehicle dynamics, the following may be concluded.

(1) A high vehicle speed during double-lane change yields bad path keeping performance, ride comfort, steering stability, and roll stability. When the vehicle speed is higher than $60 \mathrm{~km} / \mathrm{h}$, the ride comfort of this vehicle gets worse greatly.
(2) A long time delay is harmful to path keeping performance, steering stability, and roll stability and has almost no effect on the ride comfort.

Thus, a low vehicle speed ranging from $20 \mathrm{~km} / \mathrm{h}$ to $60 \mathrm{~km} /$ $\mathrm{h}$ and a small time delay less than $0.35 \mathrm{~s}$ are recommended for improving this truck's stability when going through the lane change.

In case of varying the preview distance or permit position error, the variation in vehicle trajectories at the speed of $40 \mathrm{~km} / \mathrm{h}$ is shown in Figure 14. The effects of preview distance or permit position error on the path-following ability and full vehicle dynamics are shown in Figure 15. As shown in Figures 14 and 15, a large preview distance deteriorates the path-following ability but has small effect on other dynamic responses. On the other hand, a too small preview distance leads to a hop of lateral acceleration, yaw rate, and roll angle, which conflicts with closed-loop stability and is harmful to steering control. This conclusion is consistent with that of Gillespie and MacAdam [15] and Pauwelussen [30]. The influence of permit position error on path-following ability is small at short preview distance but great at long preview distance. As shown in Figure 14, a too small or too large permit position error $(0.01 \mathrm{~m}$ or $0.8 \mathrm{~m})$ will worsen the vehicle's pathfollowing ability. In addition, large permit position error may increase vertical acceleration, lateral acceleration, yaw rate, and roll angle and reduce the handling stability and roll stability and ride comfort. The effect of preview distance and permit position error on pitch angle is small and shows fluctuation. Thus, a preview distance ranging from $10 \mathrm{~m}$ to $30 \mathrm{~m}$ and a small permit position error but more than $0.01 \mathrm{~m}$ are recommended for improving this truck's stability when moving through the lane change. A smaller permit position error should be matched with a shorter preview distance. 

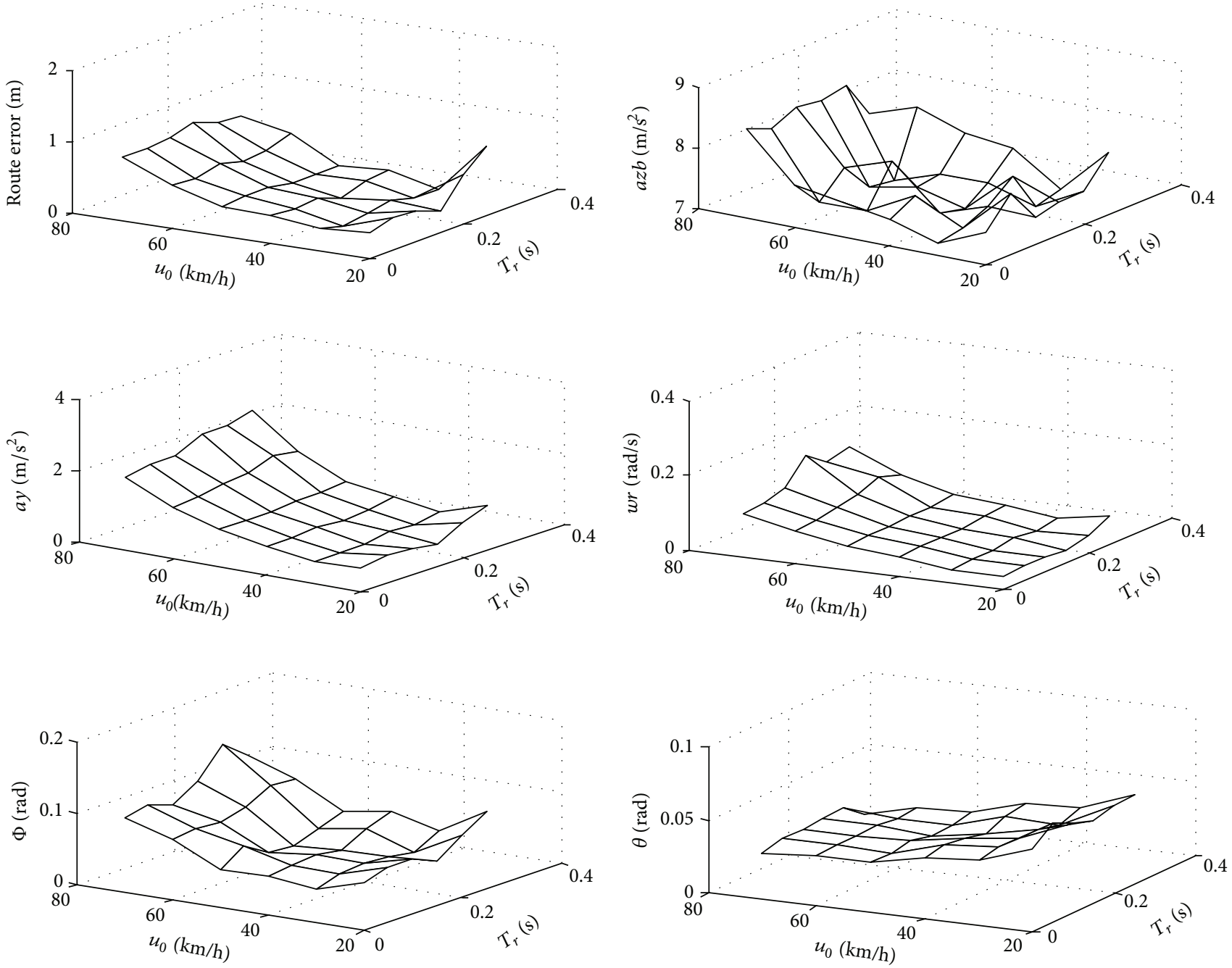

FIgURE 13: The effects of vehicle speed and driver time delay.
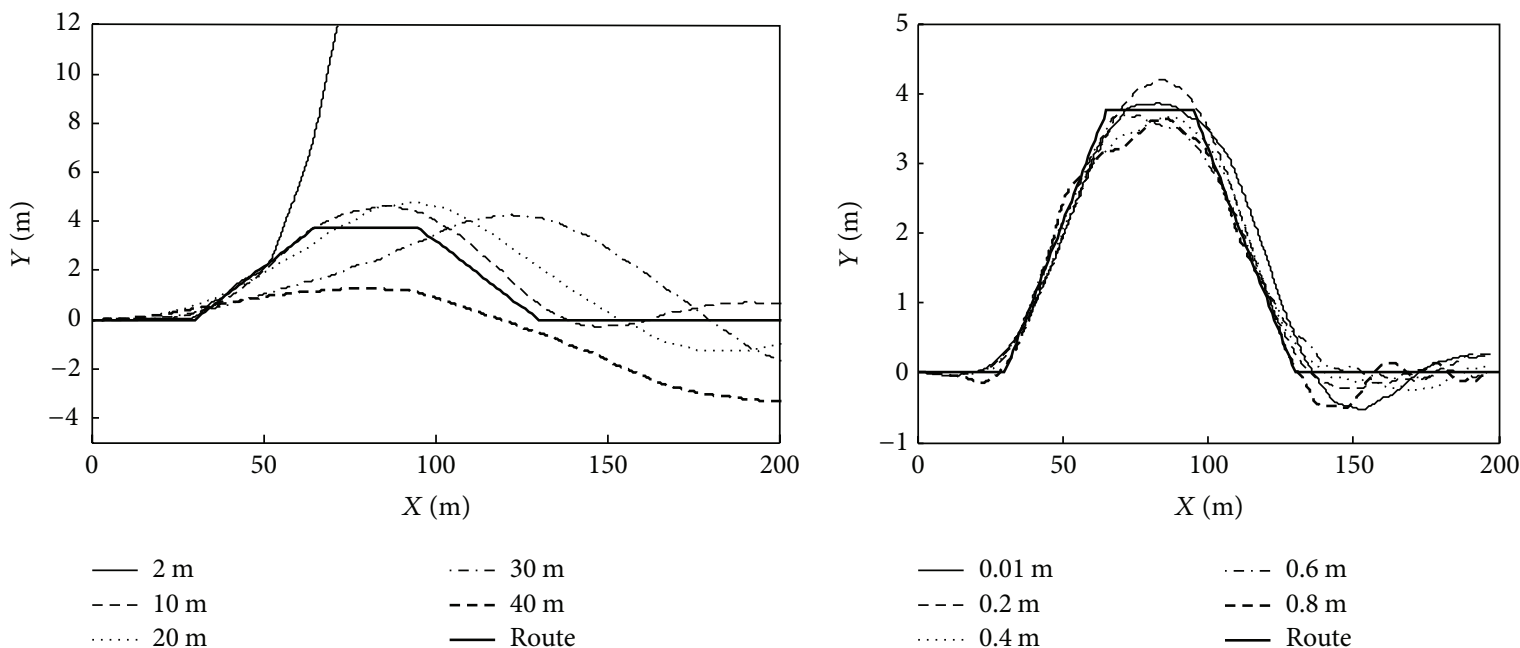

$-\cdot-30 \mathrm{~m}$
$---40 \mathrm{~m}$
- Route

$\begin{array}{ll}- & 0.01 \mathrm{~m} \\ --- & 0.2 \mathrm{~m} \\ \ldots .0 .0 & 0.4 \mathrm{~m}\end{array}$

-
--

$20 \mathrm{~m}$

Figure 14: Routes of vehicle under different preview distance and permit position error. 

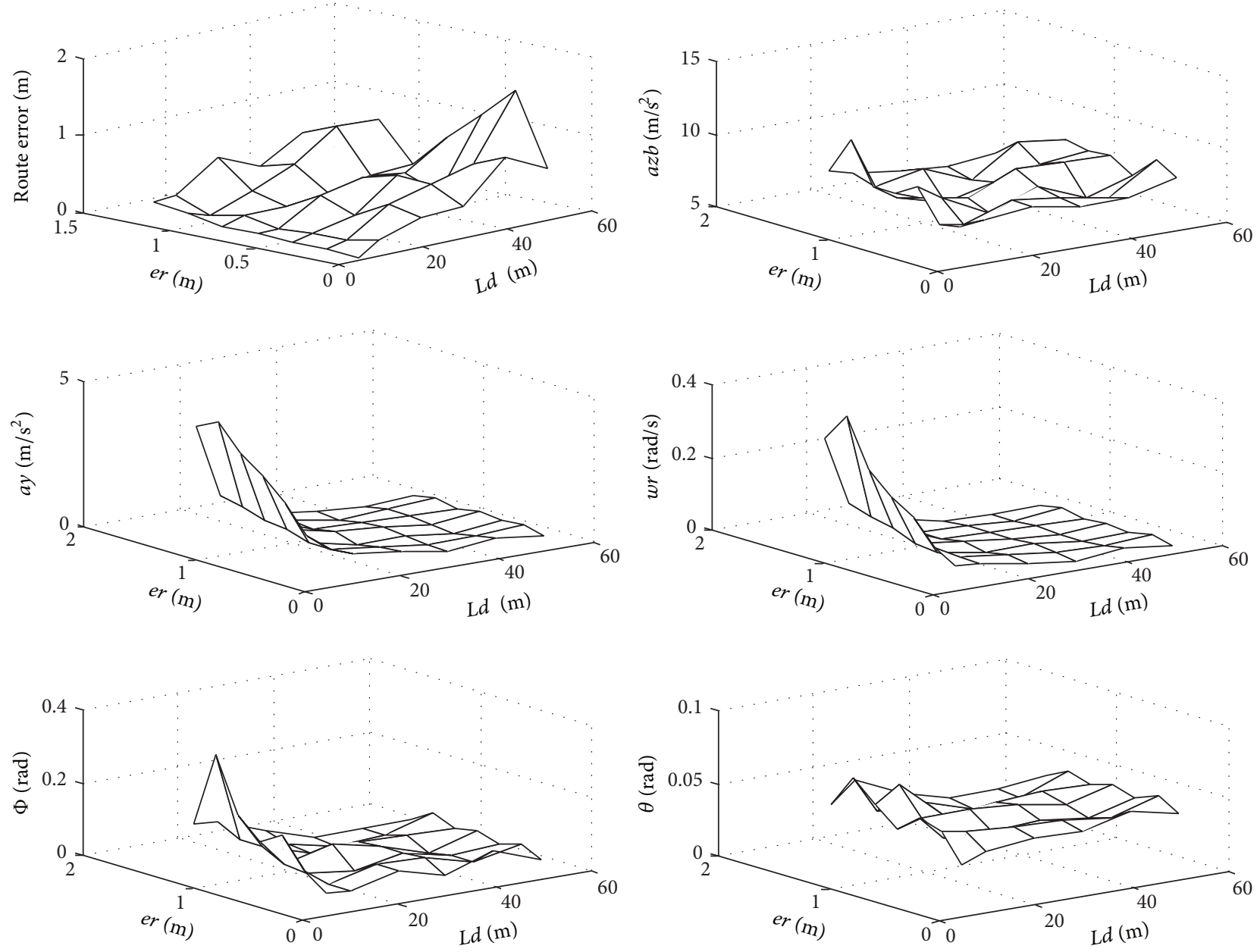

FIGURE 15: The effects of preview distance and permit position error.

\section{Conclusions}

In this paper, a nonlinear three-directional coupled lumped parameters (TCLP) model of heavy-duty vehicle considering the nonlinearity of suspension damping and tire stiffness is built and connected with a proposed modified preview driver model with nonlinear time delay. The proposed driver model is simple and has a feedback gain $2 L / d^{2}$ that is decided by wheelbase and preview distance. The validity of this presented driver-vehicle closed-loop system is verified by comparison with the test data, the traditional steering stability vehicle model, the linear vehicle model, and other driver control models. The results show that the new driver model has better lane keeping performances than the other two driver models. The coupling effects of vehicle motions and the nonlinearity of suspension damping and tire stiffness could not be neglected in turning or high speed driving situation.

The effects of driver parameters on path-following ability and full vehicle dynamics are also discussed. It is found that the high vehicle speed, large time delay, long preview distance, or big permit position error will deteriorate pathfollowing performances and handling stability. Of course, a too short preview distance or a too small permit position error is also harmful to path-following performances and handling stability. The ride comfort mainly depends on vehicle speed, preview distance, and permit position error. The key factors influencing roll characteristics are vehicle speed and time delay.

\section{Conflict of Interests}

The authors declare that there is no conflict of interests regarding the publication of this paper.

\section{Acknowledgments}

The National Natural Science Foundation of China (11472180), the Natural Science Foundation of Hebei Province (E2012210025), and the New Century Talent Foundation of Ministry of Education (NCET-13-0913) support this work.

\section{References}

[1] M. Plochl and J. Edelmann, "Driver models in automobile dynamics application," Vehicle System Dynamics, vol. 45, no. 7-8, pp. 699-741, 2007. 
[2] C. C. MacAdam, "Understanding and modeling the human driver," Vehicle System Dynamics, vol. 40, no. 1-3, pp. 101-134, 2003.

[3] K. Guo and H. Guan, "Modeling of driver/vehicle directional control system," Vehicle System Dynamics, vol. 22, no. 3-4, pp. 141-184, 1993.

[4] K. Guo, Vehicle Handling Dynamics Theory, Jiangsu Science and Technology Publishing House, Nanjing, China, 2011.

[5] R. S. Sharp, "Driver steering control and a new perspective on car handling qualities," Proceedings of the Institution of Mechanical Engineers, Part C: Journal of Mechanical Engineering Science, vol. 219, no. 10, pp. 1041-1051, 2005.

[6] T. Legouis, A. Laneville, P. Bourassa, and G. Payre, "Characterization of dynamic vehicle stability using two models of the human pilot behavior," Vehicle System Dynamics, vol. 15, no. 1, pp. 1-18, 1986.

[7] Z. Liu, G. Payre, and P. Bourassa, "Nonlinear oscillations and chaotic motions in a road vehicle system with driver steering control," Nonlinear Dynamics, vol. 9, no. 3, pp. 281-304, 1996.

[8] Z. Liu, G. Payre, and P. Bourassa, "Stability and oscillations in a time-delayed vehicle system with driver control," Nonlinear Dynamics, vol. 35, no. 2, pp. 159-173, 2004.

[9] X. D. Liu, W. Feng, and N. Kang, "Research of simulation method of tractor-semitrailer carrying liquid considering liquid sloshing," in Proceedings of the 10th National Conference on Vibration Theory and Application, pp. 581-590, Nanjing, China, October 2011.

[10] C. C. MacAdam, "Application of an optimal preview control for simulation of closed-loop automobile driving," IEEE Transactions on Systems, Man and Cybernetics, vol. 11, no. 6, pp. 393399, 1981.

[11] A. Y. Ungoren and H. Peng, "An adaptive lateral preview driver model," Vehicle System Dynamics, vol. 43, no. 4, pp. 245-259, 2005.

[12] C. I. Chatzikomis and K. N. Spentzas, "A path-following driver model with longitudinal and lateral control of vehicle's motion," Forschung im Ingenieurwesen, vol. 73, no. 4, pp. 257-266, 2009.

[13] R. S. Sharp, D. Casanova, and P. Symonds, "A mathematical model for driver steering control, with design, tuning and performance results," Vehicle System Dynamics, vol. 33, no. 5, pp. 289-326, 2000.

[14] A. J. Pick and D. J. Cole, "Neuromuscular dynamics in the driver-vehicle system," Vehicle System Dynamics, vol. 44, supplement 1, pp. 624-631, 2006.

[15] T. D. Gillespie and C. C. MacAdam, Constant Velocity Yaw/Roll Program: User's Manual, The University of Michigan Transportation Research Institute, Ann Arbor, Mich, USA, 1982.

[16] R. I. S. Raj, Influence of road roughness and directional maneuver on the dynamic performance of heavy vehicles [M.S. thesis], Department of Mechanical Engineering, Concordia University, Montreal, Canada, 1998.

[17] K. Worden, D. Hickey, M. Haroon, and D. E. Adams, "Nonlinear system identification of automotive dampers: a time and frequency-domain analysis," Mechanical Systems and Signal Processing, vol. 23, no. 1, pp. 104-126, 2009.

[18] S. H. Li, Y. J. Lu, and L. Y. Li, "Dynamical test and modeling for hydraulic shock absorber on heavy vehicle under harmonic and random loadings," Research Journal of Applied Sciences, Engineering and Technology, vol. 4, no. 13, pp. 1903-1910, 2012.

[19] X. W. Ji and Y. M. Gao, "The dynamic stiffness and damping characteristics of the tire," Automotive Engineering, vol. 5, pp. 315-321, 1994.
[20] G. Gim and P. E. Nikravesh, "A three dimensional tire model for steady-state simulations of vehicles," $S A E$, vol. 102, no. 2, pp. 150-159, 1993.

[21] J. D. Zhuang, Principles of Automobile Tire, Beijing Institute of Technology Press, Beijing, China, 1996.

[22] W.-M. Zhai, "Two simple fast integration methods for largescale dynamic problems in engineering," International Journal for Numerical Methods in Engineering, vol. 39, no. 24, pp. 41994214, 1996.

[23] Dongfeng Motor Group Company, Dongfeng DFL1250A8, DFL1250A9 Truck Chassis Refit Manual, Dongfeng Motor Group Company, 2008.

[24] S. Li, S. Yang, L. Chen, and Y. Lu, "Effects of parameters on dynamic responses for a heavy vehicle-pavement- foundation coupled system," International Journal of Heavy Vehicle Systems, vol. 19, no. 2, pp. 207-224, 2012.

[25] S. Yang, S. Li, and Y. Lu, "Investigation on dynamical interaction between a heavy vehicle and road pavement," Vehicle System Dynamics, vol. 48, no. 8, pp. 923-944, 2010.

[26] GB/T 7031-2005/ISO 8608:1995, Mechanical Vibration-Road Surface Profiles-Reporting of Measured Data, 2005.

[27] M. Li, X. Pu, and Z. Changfu, "Modeling and simulation of heavy-duty semi-trailer in extreme condition based on ADAMS," Automobile Technology, vol. 2, pp. 22-25, 2009.

[28] "Passenger cars-test track for a severe lane-change manoeuvre-part 1: double lane-change," ISO 3888-1:1999.

[29] S. H. Li, S. P. Yang, and N. Chen, "Directional control of a driver-heavy-vehicle closed-loop system," Advanced Engineering Forum, vol. 2-3, pp. 33-38, 2012.

[30] J. Pauwelussen, "Dependencies of driver steering control parameters," Vehicle System Dynamics, vol. 50, no. 6, pp. 939959, 2012.

[31] H. Imine and V. Dolcemascolo, "Rollover risk prediction of heavy vehicle in interaction with infrastructure," International Journal of Heavy Vehicle Systems, vol. 14, no. 3, pp. 294-307, 2007. 


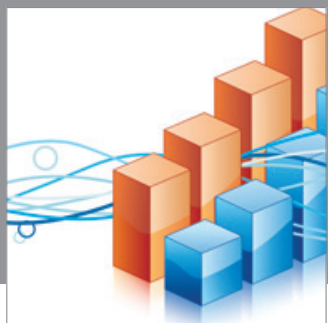

Advances in

Operations Research

mansans

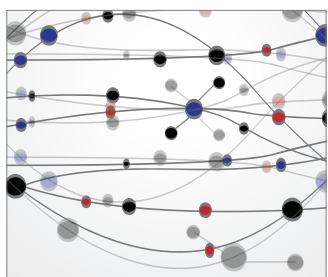

The Scientific World Journal
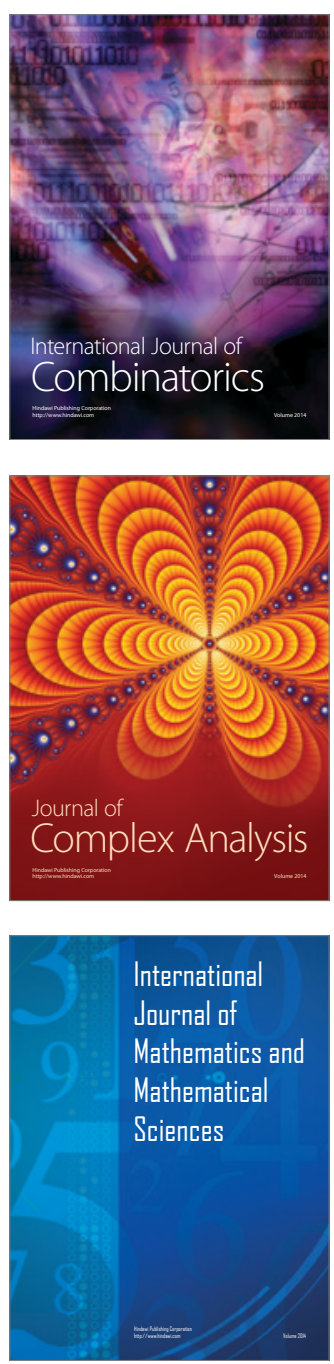
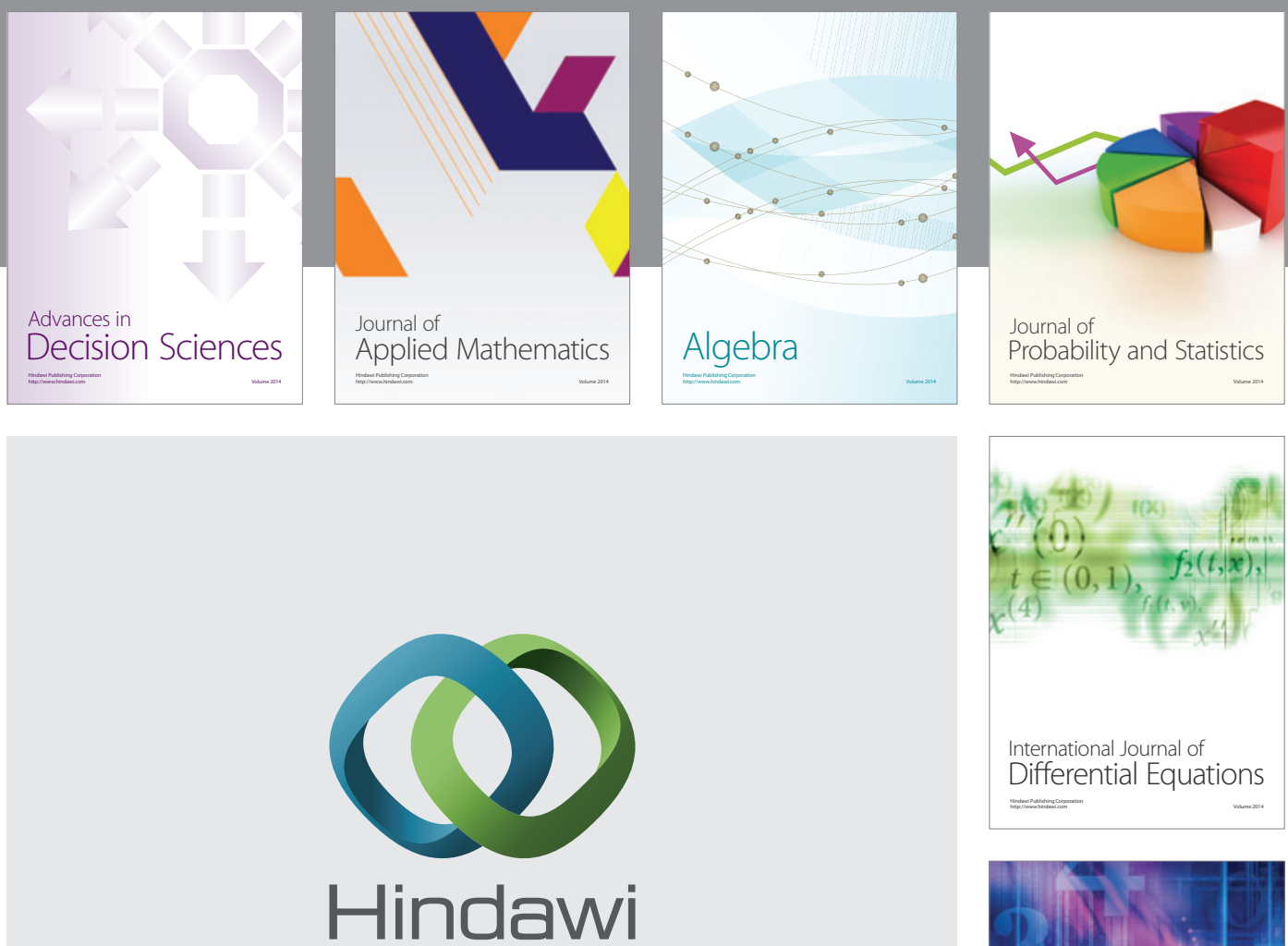

Submit your manuscripts at http://www.hindawi.com
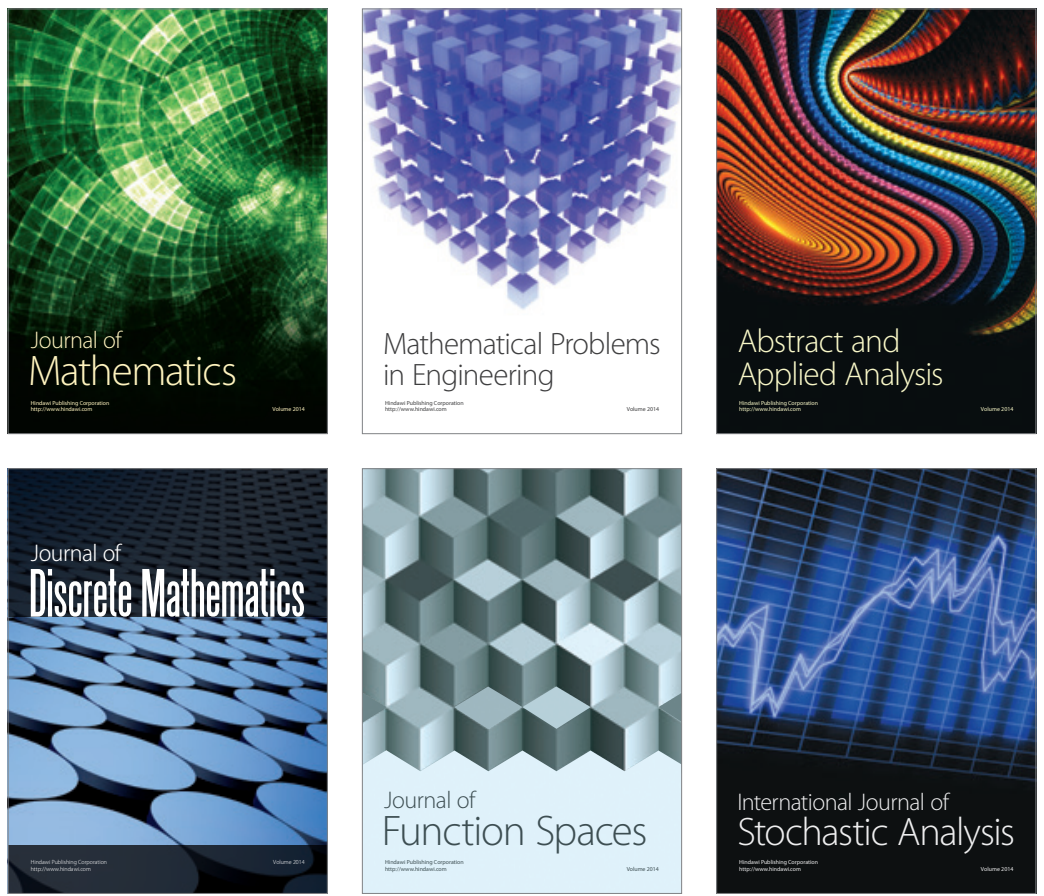

Journal of

Function Spaces

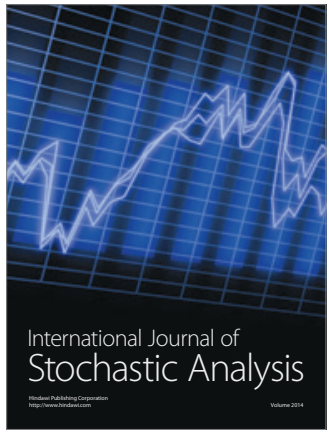

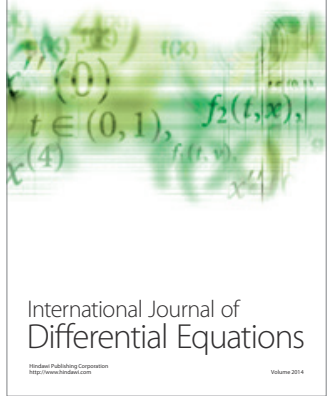
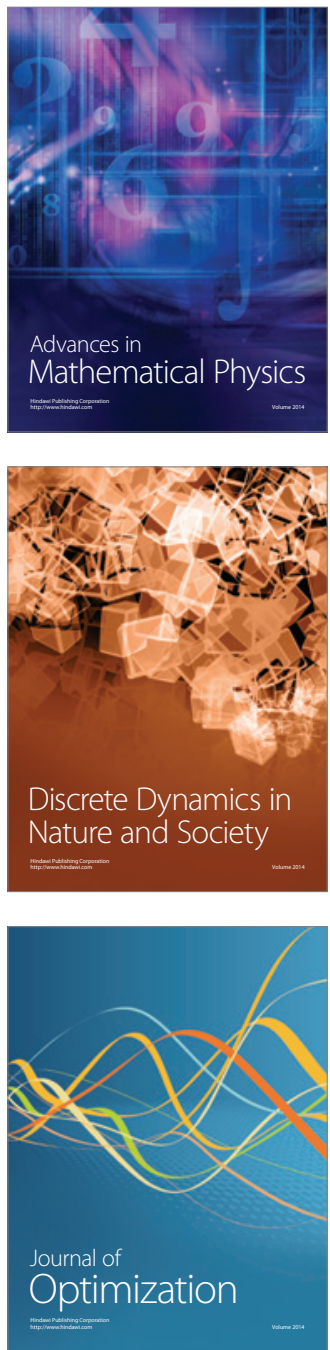